\title{
Perinatal High-Fat Diet and Bisphenol A: Effects on Behavior and Gene Expression in the Medial Prefrontal Cortex
}

\author{
Leslie M. Wise $^{a}$ Diego Hernández-Saavedra ${ }^{c}$ Stephanie M. Boas ${ }^{a}$ \\ Yuan-Xiang Pan ${ }^{c-e}$ Janice M. Juraska ${ }^{a, b}$ \\ ${ }^{a}$ Department of Psychology, University of Illinois, Champaign, IL, USA; ${ }^{b}$ Neuroscience Program, University of Illinois, \\ Champaign, IL, USA; ' Division of Nutritional Sciences, University of Illinois, Urbana, IL, USA; ${ }^{d}$ Department of Food \\ Science and Human Nutrition, University of Illinois, Urbana, IL, USA; elllinois Informatics Institute, University of \\ Illinois, Urbana, IL, USA
}

\section{Keywords}

Bisphenol A · Endocrine disruptor · MicroRNA · Maternal

behavior · Social play · Inflammation

\begin{abstract}
Both high-fat diets (HFD) and bisphenol A (BPA), an environmental endocrine disruptor, are prevalent in industrialized societies. Previous studies have detected separate effects of BPA and HFD; however, none have assessed possible interactive effects. Here, pregnant dams consumed 0,40 , or $400 \mu \mathrm{g}$ $\mathrm{BPA} / \mathrm{kg} /$ day and were fed either a control $(\mathrm{CON} ; 15.8 \% \mathrm{kcal}$ fat) or HFD ( $45 \%$ kcal fat) from gestational day 2 through parturition. The pups were individually dosed with BPA from postnatal days $(P) 1-10$, while the dams continued to consume one of the two diets. Maternal behavior increased with the HFD while the offspring's periadolescent social play decreased with BPA, but no interactive effects were observed. Neither HFD nor BPA exposure changed performance on a social recognition task, and only BPA had an effect on the elevated plus maze. BPA increased several cytokines in the medial prefrontal cortex (mPFC) of P10 males but not females. Expression of several genes related to hormone synthesis and receptors, inflammation, oxidative stress, and
\end{abstract}

() 2018 S. Karger AG, Basel

E-Mail karger@karger.com

www.karger.com/dne apoptosis in the mPFC on P10 and P90 were altered due to BPA and/or HFD exposure with rare interactive effects. BPA resulted in an increase in the gene expression of Esr1 in the mPFC of females on both P10 and P90. Epigenetic analysis on $\mathrm{P} 90$ did not show a change in methylation or in the levels of pre-mRNA or microRNA. Thus, perinatal BPA and HFD have separate effects but rarely interact.

c) 2018 S. Karger AG, Basel

\section{Introduction}

The early environment, including maternal care, can have long-lasting effects on the cellular composition [1] and behavior [2] of rodent offspring with broad generalization to other mammalian species [3,4]. Research in animal models has suggested that endocrine disruptors and dietary intake can alter maternal behavior, offspring behavior, and gene expression. Both endocrine disruptors and high-fat diets (HFD) have also been independently found to induce inflammation in the brain and periphery [5-7]; however, few studies have investigated their possible interactions [8]. This may have implications for humans given the ubiquitous exposure of endo- 
crine-disrupting chemicals in our environment and HFD in Western society.

Endocrine disruptors are compounds that interact with hormone receptors as agonists, antagonists, or a mixture of both. Thus, endocrine disruptors can inappropriately activate a hormone receptor, even when the hormone is not present, and they can block the actions of hormones. Given that hormones play a role in the development of the nervous system and that hormonal receptors are present during this crucial time, endocrine disruptors can alter the course of development. One such endocrine disruptor is bisphenol A (BPA), a chemical found in polycarbonate plastics, certain dental sealants, and epoxy resins that line canned foods [9]. BPA binds with the highest affinity to estrogen-related receptor $\gamma$ $(\mathrm{ERR} \gamma)$, but also to estrogen receptor (ER) $\alpha, E R \beta$, and androgen and thyroid receptors [10-14]. Exposure to BPA has been found to change gene expression, neuroanatomy, and several types of behavior. Maternal behaviors during BPA exposure alter the time spent licking and grooming the pups as well as the time spent nursing in an arched-back position $[15,16]$. Perinatal exposure to BPA also causes long-term effects on social, sexual, and anxiety behavior in adolescent and adult animals, as well as the number of neurons in a number of neural areas, including the medial prefrontal cortex (mPFC) [17-22]. At a molecular level, perinatal BPA exposure has been found to affect gene expression of Esr1, Esr2, Errg, as well as dopamine and serotonin receptor-related proteins in the PFC of young rats on postnatal day (P) 21 and mice on P28 [16, 23]. Furthermore, the differences in gene expression of Esr1, Esr2, and Errg have been found to be due to changes in DNA methylation in juvenile mice [16]. Based on the evidence of expression and methylation changes within the cortex and behavior changes in adolescence and adulthood, perinatal BPA exposure has a significant effect on the offspring.

HFD can also affect behavior, inflammation, and gene expression. The existing literature presents conflicting evidence of its effect on maternal behavior with both increases and decreases of positive maternal behaviors being reported [24-26]. In offspring, there are indications of HFD influencing social play and cognitive and anxiety behaviors [27-29]. Gestational HFD with $60 \%$ fat content has been found to increase proinflammatory cytokine expression of IL-1 $\beta$, microglial activation in the hippocampus of adult male and female offspring [28], and the level of IL-6 in the frontal cortex of adult male offspring [30]. HFD (45\%) has also been found to alter gene expression in the hippocampus and performance on the Morris wa- ter maze [31] as well as signaling in cultured primary neural stem cells [32]. Research on nonhuman primates also found alterations in the gene expression of serotonin receptors in male and female offspring following maternal HFD (32\% fat) [29]. Gestational HFD (60\% fat) through $\mathrm{P} 40$ is known to affect expression of oxytocin-related genes in the mPFC on P40 [27], and maternal HFD (60\% fat) through gestation and lactation also alters opioid and dopamine-related proteins in the mPFC of adult male mice [33]. Few studies have investigated the effect of HFD and BPA on gene expression of hormone receptors in the PFC despite interactions of estrogen receptors and inflammation in other brain areas [34].

Although separate exposure to HFD and BPA is known to alter maternal behavior, offspring behavior, gene expression, and inflammation in the brain and periphery [5-7], the combined effects of both factors have not been investigated. Additionally, previous work in our laboratory found a higher number of neurons and glia in the mPFC of adult male, but not female, rats following perinatal BPA exposure [22]. The higher number of neurons found in male rats may have a parallel in the higher number of neurons found in a subset of children with autism, a male-biased neurological disorder with impaired social interactions as a core characteristic [35]. To further investigate this similarity, the current study focuses on the gene expression and cytokine levels in the mPFC, as well as social behaviors. We examine the possible interactive effects of BPA exposure and HFD during gestation and the early postnatal period on maternal care, as well as offspring behavior, gene expression, and cytokine levels in the mPFC.

\section{Methods}

\section{Breeding}

Male and female Long Evans hooded rats ( $n=58$ of each sex) purchased from Harlan Laboratories (now Envigo, Indianapolis, IN, USA) were housed in our vivarium for at least 1 week before being paired for breeding. They were kept on a 12:12 light/dark cycle and were allowed food and water ad libitum. Precautions were taken to reduce the environmental exposure to endocrine disruptors. All animals were housed in BPA-free polysulfone cages and fed either a low phytoestrogen diet (Harlan 2020X; Teklad Diets, Madison, WI, USA) or the specialized diet (see Diet) during gestation through P10; water was reverse osmosis filtered in glass bottles. All procedures were approved by the University of Illinois Institutional Care and Use Committee and adhere to the National Institute of Health guidelines on the ethical use of animals.

Breeding pairs were placed in suspended wire bottom cages and checked daily for the presence of sperm plugs. The breeding animals were paired for a maximum of 6 nights. If no sperm plug was 
Fig. 1. Timeline of behavior and tissue collection following perinatal BPA and HFD exposure.

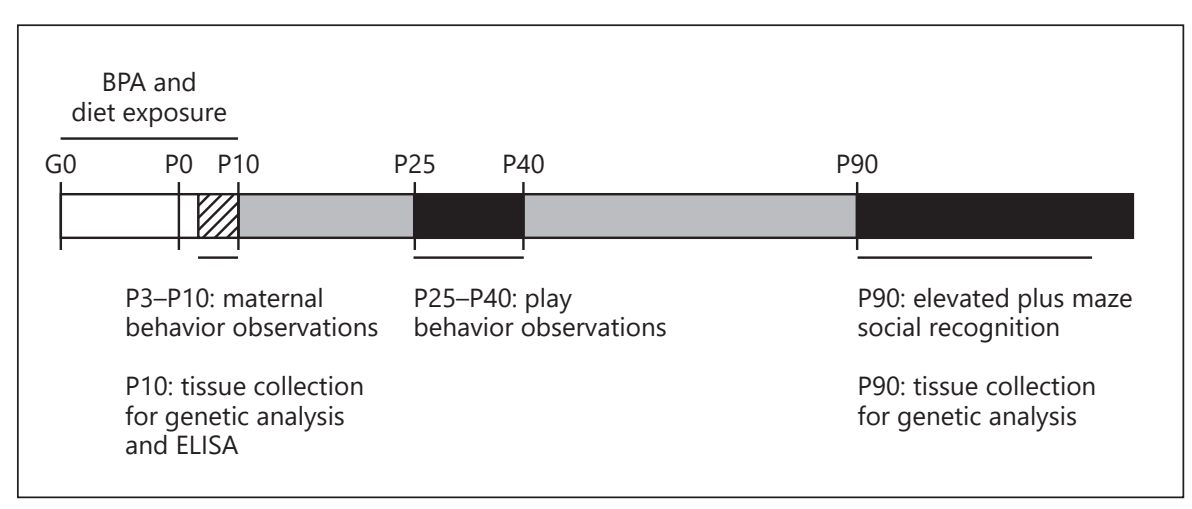

detected after 6 nights, the male was removed and another male introduced. The day a sperm plug was detected was recorded as gestational day $(\mathrm{G}) 0$, and the dams were singly housed in a polysulfone shoebox cage. From the first day of pregnancy, each female was assigned to 1 of 6 groups. The number of litters for the control diet and BPA exposures were: $0 \mu \mathrm{g}$ BPA $/ \mathrm{kg}(0 \mathrm{BPA})=8 ; 40 \mu \mathrm{g} \mathrm{BPA} /$ $\mathrm{kg}=10$; and $400 \mu \mathrm{g} B \mathrm{AA} / \mathrm{kg}=10$. The number of litters for HFD and BPA exposures were: $0 \mathrm{BPA}=10 ; 40 \mu \mathrm{g} \mathrm{BPA} / \mathrm{kg}=10$; and 400 $\mu \mathrm{g} \mathrm{BPA} / \mathrm{kg}=10$. The experimental design is illustrated in Figure 1.

\section{BPA Dosing}

BPA was suspended in tocopherol-stripped corn oil at $0,0.1$, or $1.0 \mathrm{mg} \mathrm{BPA} / \mathrm{mL}$ in order to administer 0 (control), 40 , or $400 \mu \mathrm{g}$ $\mathrm{BPA} / \mathrm{kg}$, respectively. Our laboratory has previously found effects of the 40- and 400- $\mu \mathrm{g}$ BPA/kg doses [22,36]. Tocopherol-stripped corn oil has no estrogenic activity as evidenced by no increase in uterine weight of prepubertal mice [37]. To dose the adult dams, the required amount $(0.4 \mu \mathrm{L} / \mathrm{g}$ body weight $)$ was pipetted onto half a cookie (Newman's Own organic alphabet cookie, vanilla flavor) and given to the animals. The animals readily consumed the cookie making this route of exposure nonstressful and similar to human ingestion of BPA. On G0 and G1, the dams were given half a cookie with $0.4 \mu \mathrm{L} / \mathrm{g}$ tocopherol-stripped corn oil. Starting on G2 through parturition, the dams were given the cookie with the assigned BPA dose. The day of birth was recorded as P0, and the litters were not disturbed. Then, daily from P1 to P10, each pup was individually dosed the assigned solution (same as dam) via pipetting directly into its mouth because lactational transfer of BPA is very low [38]. A plastic pipette tip was gently eased into the pup's mouth towards the back of the tongue. The oil was dripped onto the pup's tongue, and the experimenter slowly administered small amounts of oil to avoid damaging oral tissue and pulmonary aspiration. The pups easily and quickly consumed the small volume of oil $(0.4 \mu \mathrm{L} / \mathrm{g}$ body weight). Although the resulting level of BPA in the brain was not measured in the current study, previous research has shown that oral administration results in BPA being present in brain tissue of both fetal and early postnatal animals $[39,40]$.

\section{Diet}

Starting on G0 through P10, the dams were fed either a control diet (CON; D10012G, Research Diets Inc., NJ, USA) or HFD (D12451, Research Diets Inc.). The CON diet comprised 15.8\% kcal fat, $20.3 \% \mathrm{kcal}$ protein, and $63.9 \% \mathrm{kcal}$ carbohydrate. The HFD consisted of $45 \% \mathrm{kcal}$ fat, $20 \% \mathrm{kcal}$ protein, and $35 \% \mathrm{kcal}$ carbohydrate. This diet was chosen because there is evidence that the Western diet has 35\% fat on average [41], making the 60\% HFD out of range for most people. The animals were allowed access to food ad libitum. Numbers and sex ratio of the pups and daily body weight for dams and pups were recorded.

\section{Maternal Behavior Observations}

The dams were observed with their litters from P3 to P10 during the dark cycle using night vision goggles by an observer blind to treatment groups. The dams' behavior was recorded every $3 \mathrm{~min}$ for $90 \mathrm{~min}$ (30 observations/night). The behavioral classifications were nursing, licking of pups, pup retrieval, nest building, and being away from the nest. When nursing and licking of pups occurred simultaneously, licking was preferentially recorded. Pup retrieval and nest building were rarely observed and, therefore, not included in the analyses.

\section{Periadolescent Social Behavior}

Two animals of the same sex and treatment (not cage mates) were paired to assess social behavior. The method of examining play in pairs of same-treatment animals is often used in the literature $[42,43]$. Animals between ages P26 and P40 were isolated in individual cages for $1 \mathrm{~h}$ before each session and were then paired for social assessments in a neutral cage on 4 consecutive days $1 \mathrm{~h}$ before the start of the dark cycle. The animals' behavior was observed for $20 \mathrm{~min}$, and 1-min time point sampling was used to classify the behaviors: sniffing, wrestling, chasing, passive contact (no play, but touching), and solitary (no play and not touching). After data collection, the animals were returned to their home cage. All animals in the study were assessed, and then the average from each sex within a litter was used in the statistical analysis.

\section{Elevated Plus Maze}

On P90 (adulthood), 1 male and 1 female from each litter were tested for anxiety behavior using the elevated plus maze (EPM). The floor of the EPM apparatus was $50 \mathrm{~cm}$ tall with 2 open arms and 2 closed arms that were each $50 \mathrm{~cm}$ long and $10.5 \mathrm{~cm}$ wide. The 2 closed arms had walls $33.5 \mathrm{~cm}$ tall. Each animal was placed on the center and allowed to explore the maze for one 5-min trial. Time spent in each arm, time in the center, and the number of entries into each arm were recorded. The operational definition of "entry" was more than half of the animal's body had to enter the arm in order to be counted and timed. 


\section{Social Recognition}

On P90, another set of littermates not tested (see Elevated Plus Maze) were assessed for social memory in the social recognition task using same-sex juveniles (P21-P30). Before the task began, each juvenile was marked on its back with a differently colored nontoxic marker for easy identification. There were 3 days of habituation, which were identical to testing except the delay period was always $30 \mathrm{~min}$. Data were collected during habituation but were not included in the data analysis. Following habituation, the delay periods $(15,45,90$, or $120 \mathrm{~min})$ were randomized between animals for the 4 days of testing. To test social memory, adult animals were introduced and allowed to investigate a same-sex juvenile for $30 \mathrm{~s}$. After the initial introduction, the juvenile animal was removed, and the adult was placed back with its cage mate for a delay period. After the delay period, the same juvenile (familiar) and a novel juvenile were placed in a cage with the adult. The time the adult spent investigating each juvenile was recorded for $3 \mathrm{~min}$. In theory, an animal with good social memory will spend more time investigating the novel juvenile rather than the familiar juvenile. The adult animals never saw the same juveniles on more than 1 day.

\section{ELISA}

On P10, 1 male and 1 female from each litter were removed $1 \mathrm{~h}$ after BPA treatment. The remainder of the litter was allowed to age into adulthood. Each pup was anesthetized using $\mathrm{CO}_{2}$ and then quickly decapitated. The brain was immediately removed and snap frozen in liquid nitrogen. The PFC was excised while the brain was frozen and 1 hemisphere was used for ELISA while the other was used for gene expression analysis (RNA Isolation and 1-Step Real-Time Quantitative PCR). The hemispheres were stored in a $-80^{\circ} \mathrm{C}$ freezer. All tissue was coded to conceal BPA treatment. A precoated ELISA plate (Signosis, Santa Clara, CA, USA) was used to analyze the levels of cytokines. Each plate could bind and measure tumor necrosis factor (TNF) $\alpha$, transforming growth factor (TGF)- $\beta$, MCP-1, interleukin (IL)- $1 \alpha$, IL-1 $\beta$, IL-6, IL-15, and vascular endothelial growth factor (VEGF) simultaneously, allowing for a survey of inflammatory factors. The second hemisphere of the P10 mPFC was lysed following the manufacturer's instructions. Briefly, $1 \mathrm{~mL}$ of cell lysis buffer/100 mg of tissue was homogenized on ice. The lysate was centrifuged to separate the tissue from the supernatant, which was then diluted to 100 $\mu \mathrm{g} / 100 \mu \mathrm{L}$ per well and used for the protein analysis. The samples were run in duplicate and incubated in the plate overnight followed by 3 washes. A biotin-labeled antibody (specific to each cytokine) was added and allowed to incubate for $4 \mathrm{~h}$ followed again by 3 washes. Next, a streptavidin-HRP conjugate was added to each well, incubated for $45 \mathrm{~min}$, and followed by 3 washes. Finally, HRP substrate was added and allowed to incubate for $30 \mathrm{~min}$ before the addition of a stop solution to each well. The optical density of each well was determined with a microplate reader at 450 nm within 5 min.

\section{RNA Isolation and 1-Step Real-Time Quantitative PCR}

Genes related to hormone receptors (Esr1, Esr2, Errg, Ar), steroid synthesis (StAr, Ldlr, Cyp11a1), inflammation (Aif1, C4a, C4b), apoptosis (Casp3), and oxidative stress (Cat, Sod1, Sod2, Glrx) were chosen for investigation. Before genetic analysis, 1 hemisphere from each animal was randomly selected, and total RNA was isolated using TRI reagent (Sigma, St. Louis, MO, USA), followed by Direct-zol ${ }^{\mathrm{TM}}$ RNA MiniPrep (Zymo Research, Irvine, CA, USA) according to the manufacturer's instructions. Reverse transcription was performed using the high capacity cDNA reverse transcription kit (Applied Biosystems, Foster City, CA, USA). Quantitative real-time PCR was performed using the StepOnePlus ${ }^{\mathrm{TM}}$ real-time PCR system with Power SYBR ${ }^{\circledR}$ Green PCR master mix (ThermoFisher Scientific, Waltham, MA, USA) using the respective forward and reverse primers for each gene (online suppl. Table S1; see www.karger.com/doi/10.1159/000494879 for all online suppl. material), and were designed by Vector NTI software (ThermoFisher Scientific) and synthesized by Integrated DNA Technologies (Coralville, IA, USA). Standard curves with a slope of -3.30 (SEM 0.30) and $R^{2} \geq 0.99$ were accepted. A housekeeping gene ribosomal protein L7a (RpL7a) whose expression was not affected by treatment was used to normalize the gene expression data.

\section{MRI, RNA Isolation, and 1-Step Real-Time Quantitative PCR}

On P90, 1 male and 1 female from each litter were scanned for fat and lean mass in a magnetic resonance imaging (MRI) system. Following the scan, the animals were euthanized via $\mathrm{CO}_{2}$, and the brain was immediately removed. The cortex was excised, snap frozen in liquid nitrogen, and stored at a $-80^{\circ} \mathrm{C}$ in a freezer. All tissue was coded to conceal the BPA treatment. The same genes analyzed in the P10 group were analyzed, and identical methods were used.

\section{Genomic DNA Isolation and Methylation-Sensitive PCR}

\section{Analysis of Esr1}

Frozen cortex (50 mg) from P90 animals was ground in liquid nitrogen, and genomic DNA was then isolated using ZR Genomic DNA $^{\text {TM }}$ Tissue MiniPrep (Zymo Research, Irvine, CA, USA) per manufacturer's instruction. Genomic DNA was bisulfite converted using the EZ DNA Methylation-Gold ${ }^{\mathrm{TM}}$ kit (Zymo Research) following the manufacturer's instructions. Quantitative PCR (qPCR) used $20 \mathrm{ng}$ of genomic DNA as the template using Power SYBR Green PCR Master mix as the reporter. Primers used for each genomic region were designed using the MethPrimer website [44], to create 4 primer sets that targeted the previously described promoter of Rattus norvegicus Esr1 (ENST00000440973.1) [16]. Primer information is in the online supplementary Figure S1. A serial dilution from a reaction combining 1 sample from each experimental group was used to create an internal standard curve for quantification. Data are presented as the percent methylation

Methylation $(\%)=100 /\left[1+2^{[1.33-[\text { CtUnmeth }- \text { CtMeth }] /-2.27]}\right]$.

\section{Identification of miRNAs Targeting Esr1 $33^{\prime}$-UTR}

Further exploration of epigenetic mechanisms was undertaken by analyzing the expression levels of 3 microRNAs (miRNAs) associated with Esr1. To identify rat miRNAs that might target Esr1 3'-UTR, a 3-pronged analysis was used. First, a bioinformatic approach was used to map the $3^{\prime}$-UTR of the $R$. norvegicus Esr 1 gene in miRDB (http://www.mirdb.org/), TargetScan (http://www.targetscan.org/), and PicTar (http://pictar.mdc-berlin.de/) to predict miRNAs that interact with Esr1. Then, a miRNA family that is broadly conserved across vertebrates targets the Esrl gene and bound by BPA was found, to facilitate potential generalizations across species in the future. The final miRNA candidates were selected based on families that overlapped in the 3 approaches: rno-mir-19b-3p (MIMAT0000788), rno-mir-221/222-3p (MIMAT0000890), and rno-mir-22-3p (MIMAT0000791). Quantifi- 
Fig. 2. Maternal behavior assessment (data shown as means \pm SEM in this and all subsequent figures). a Dams exposed to CON diet spent more time away from the nest compared to the HFD-exposed dams, ${ }^{*} p<$ 0.05. There was no effect of BPA. b Dams exposed to CON diet spent marginally less time nursing the pups, $p=0.055$. The data are collapsed across BPA treatment because there was no effect of BPA exposure. c Dams exposed to $400-\mu \mathrm{g}$ BPA/kg spent marginally less time licking the pups than 0 -BPA dams, $p=0.057$. The data are collapsed across diet because there was no effect of diet.

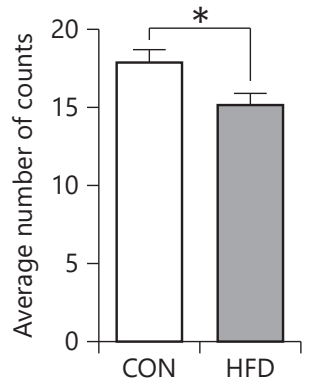

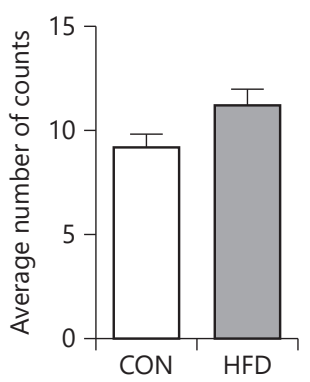

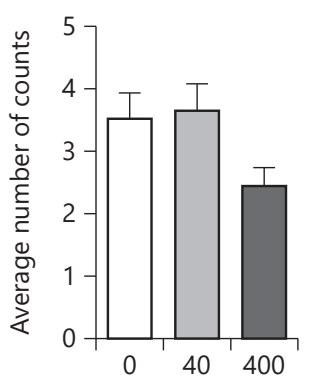

C BPA, $\mu \mathrm{g} / \mathrm{kg} /$ day cation of specific miRNA was achieved through individual reverse transcription of previously isolated RNA for enrichment, followed by qPCR with the commercially available TaqMan probes for rnomir-19b-3p (assay ID: rno478264_mir [cat. No. A25576]), rnomir-221-3p (assay ID: rno481005_mir [cat. No. A25576]), and rno-mir-22-3p (assay ID: rno481004_mir [cat. No. A25576]), following the manufacturer's instructions. All miRNA content was normalized to a U6 housekeeping snRNA (NCBI accession: NR_004394; assay ID: 001973 [cat. No. 4440887]). Specific localization of each miRNA within the $3^{\prime}$-UTR of the Esr1 rat gene (4037 bp) is illustrated in online supplementary Figure S2, where only rno-mir-19b-3p and rno-mir-22-3p showed at least 2 individual binding sites along this region. Seed sequences and binding sequences within Esrl are shown in online supplementary Figure S2.

\section{Statistical Analyses}

The growth curve for the dams' gestational body weights was analyzed with a 3 (BPA treatment) $\times 2$ (diet) repeated-measure linear mixed model with a first-order ante-dependence covariance structure (determined by small Akaike's information criterion). Litter size, sex ratio, as well as each maternal behavior (nursing, licking, and time away from nest) were analyzed with 3 (BPA treatment) $\times 2$ (diet) ANOVAs. For every measure, only 1 animal of each sex was used or the animals within the litter were averaged, and litter was the unit used for the analysis (e.g., social play). A 3 $($ BPA treatment $) \times 2($ diet $) \times 2($ sex $)$ ANOVA was used to analyze the difference in pup weights on both P1 and P10. The analysis of MRI data was completed on each sex separately given the known sex difference in body weight.

To analyze the periadolescent social behavior, sniffing, chasing, and wrestling were combined into one "social play behavior" category. In order to use only 1 measure per litter, the average counts of each category per litter were calculated and used in the analysis. Each behavior was averaged across days 1-2 and 3-4. A 3 (BPA treatment $) \times 2($ diet $) \times 2($ sex $) \times 2$ (days) repeated-measure $\mathrm{ANO}$ VA was used to analyze the play behavior data. Significant interactions were further analyzed using Tukey's LSD post hoc test.

A 3 (BPA treatment) $\times 2$ (diet) $\times 2$ (sex) ANOVA was used to analyze the EPM data. The same analysis was used to assess the percent of time spent investigating the novel juvenile at each delay of the social recognition task and the gene expression data col- lected from the P10 and P90 cortex. To analyze the ELISAs, percent change from the control group (CON diet/0 BPA) was calculated for each cytokine, and then a 3 (BPA treatment) $\times 2$ (diet) $\times 2($ sex $)$ ANOVA with plate number as a cofactor was used to analyze the percent change for each cytokine. Tukey's LSD was used for post hoc tests. When analyzing the effects of BPA treatment, each dose was only compared to the control (0 BPA) group. Significant differential expression of miRNA data was defined as a fold change greater than 0.5 .

\section{Results}

\section{Maternal and Offspring Characteristics}

Neither BPA nor HFD had a significant effect on gestational body weights, litter size, or sex ratio (data not shown). There were also no significant differences in offspring body weights on $\mathrm{P} 1$; however, BPA treatment differences emerged by $\mathrm{P} 10, \mathrm{~F}(2,106)=5.48, p=0.005$, with the $40-\mu \mathrm{g} \mathrm{BPA} / \mathrm{kg}$ group weighing less than the 0-BPA group $(p=0.002)$. There were no effects on body weight or body composition in adult rats as assessed by MRI (data not shown).

\section{Maternal Behavior}

The HFD dams spent more time in the nest than the CON diet dams; $F(1,52)=0.25, p=0.016$ (Fig. 2a). There was also an increase in the amount of time the HFD dams spent nursing the pups that was close to significant, $\mathrm{F}(1$, 52 ) $=3.84, p=0.055$ (Fig. 2b). There was no effect of BPA treatment and no interaction on these measures. BPA had a near to significant effect on licking behavior, $\mathrm{F}(2,52)=$ 3.03, $p=0.057$ (Fig. 2c), with the 400- $\mu$ g BPA/kg exposure group spending less time licking the pups than the 0-BPA group ( $p=0.055)$. Licking was not affected by diet and there was no interaction. 

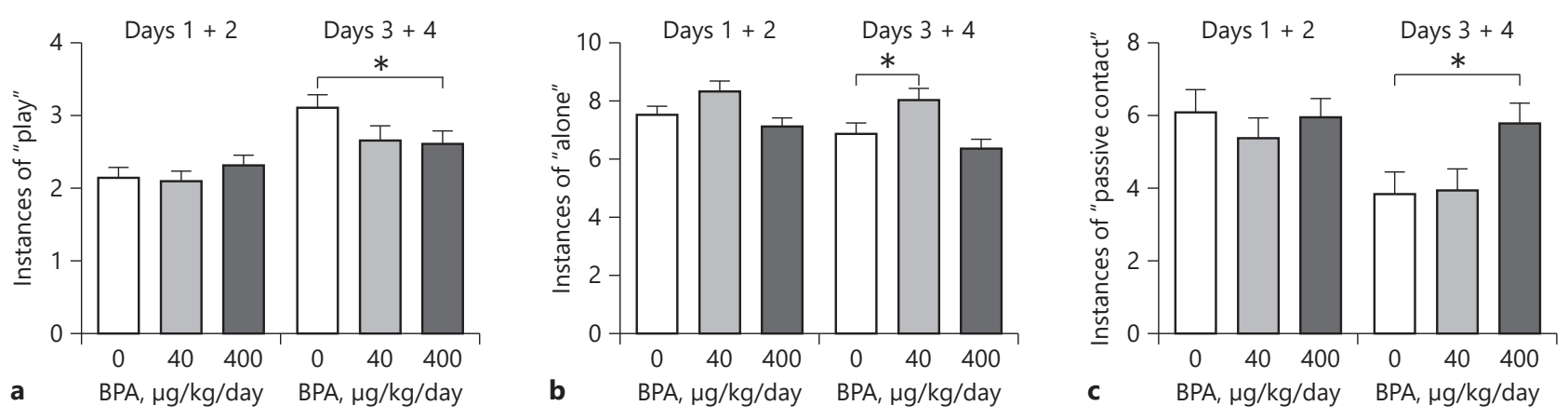

Fig. 3. BPA and social behavior separated into days 1-2 and 3-4 of testing sessions collapsed across sex because there were no interactions between sex and BPA. The data are also collapsed across diet. a 0 -BPA animals engaged in more play behavior than the animals exposed to $400 \mu \mathrm{g}$ BPA/kg/day. b The animals exposed to $40 \mu \mathrm{g}$ $\mathrm{BPA} / \mathrm{kg} /$ day spent more time alone than the 0-BPA animals. c Animals exposed to $400 \mu \mathrm{g}$ BPA/kg/day engaged in more passive contact than did the 0-BPA animals.

\section{Periadolescent Social Behavior}

There was a significant interaction between day and BPA treatment for play, $\mathrm{F}(2,160)=6.34 ; p<0.01$ (Fig. 3a). No significant differences were found on days 1 and 2 of play behavior; however, BPA treatment differences emerged on days 3 and 4. Play behaviors (sniffing, wrestling, and chasing) were significantly higher in the 0 -BPA animals than in the $400-\mu \mathrm{g} \mathrm{BPA} / \mathrm{kg}$ animals $(p<0.05)$, while the $40-\mu \mathrm{g}$ BPA $/ \mathrm{kg}$ animals also appeared to show a decrease in play; the difference with the control animals was not significant. There was also a main effect of sex in the amount of play behavior, with males exhibiting more play than females, $\mathrm{F}(1,160)=6.70, p<0.05$. There were no main effects of BPA treatment or diet.

There was a significant day-treatment interaction for time alone, $\mathrm{F}(1,160)=4.00, p=0.047$ (Fig. 3b). Again, days $1-2$ were not different, while on days $3-4$, the $40-\mu \mathrm{g}$ $\mathrm{BPA} / \mathrm{kg}$ animals spent more time alone than the 0-BPA animals $(p<0.05)$. There was a significant main effect of sex in the amount of time spent alone, $\mathrm{F}(1,160)=14.08$, $p<0.001$, with females spending more time alone than males. There were no significant differences in time alone based on maternal diet.

For passive contact, there was also a significant interaction between days and BPA treatment, $\mathrm{F}(2,160)=5.67$, $p<0.01$ (Fig. 3c). Once again, the differences did not occur on days $1-2$ but on days $3-4$; the $400-\mu \mathrm{g} \mathrm{BPA} / \mathrm{kg}$ animals spent significantly more time in passive contact than the 0 -BPA group $(p<0.05)$. There were no significant main effects of BPA or diet.
In each of the social behaviors, there was no significant BPA treatment-sex interaction, which would have suggested an attenuation or introduction of sex differences due to BPA treatment.

\section{Elevated Plus Maze}

There were no significant differences due to BPA or diet in the EPM for any of the measures (time in open arms, time in closed arms, number of crossings into the open arms, and number of crossings into the closed arms). There was a significant sex difference in the number of entries into open arms, with females entering the open arms more often, $\mathrm{F}(1,100)=8.52, p<0.01$ (Fig. 4). This is a frequently observed sex difference in the EPM [45].

Previous research has shown a reversal of sex differences with BPA-exposed males becoming less anxious [46]. In order to compare our results to previous literature, the analysis was restricted to the CON diet animals. There was a significant sex-BPA treatment interaction in the time spent in the closed arms, $\mathrm{F}(2,62)=3.84, p<0.05$, and time spent in the open arms, $\mathrm{F}(2,62)=3.69, p<0.05$. Post hoc analysis found a significant sex difference between males and females in the time spent in the closed arms $(p<0.01)$ and time spent in the open arms $(p<0.01)$, and $400 \mu \mathrm{g}$ BPA $/ \mathrm{kg} /$ day abolished the sex difference. Males showed a significant dose-dependent increase in the time in open arms with $\mathrm{BPA}$ treatment, $\mathrm{F}(2,35)=$ $3.70, p<0.05$, suggesting an anxiolytic effect of BPA. Females did not show significant differences due to BPA treatment. 


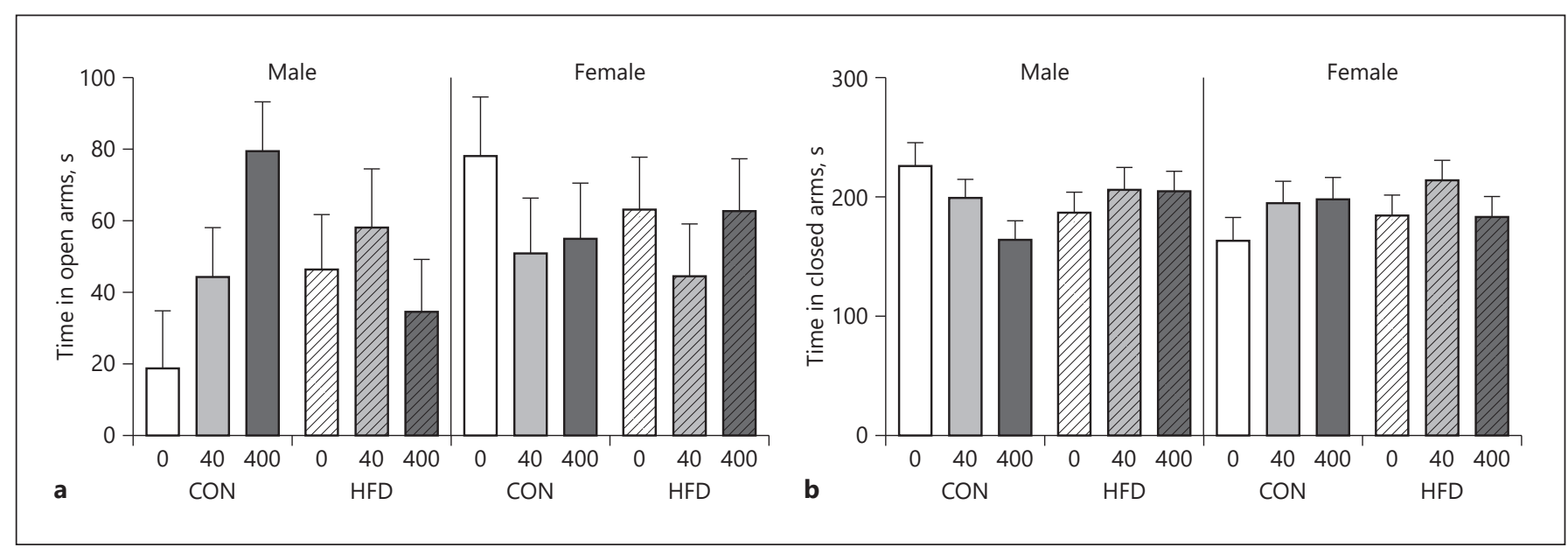

Fig. 4. Perinatal BPA $(0,40$, or $400 \mu \mathrm{g} / \mathrm{kg} /$ day $)$ and HFD exposure did not have a significant long-term effect on behavior in the EPM (see also the section Elevated Plus Maze for CON animals alone). a Time in the open arms. $\mathbf{b}$ Time in the closed arms.

Fig. 5. Perinatal BPA and HFD exposure did not result in significant long-term alterations in social recognition in adult animals (collapsed across sex). Means \pm SEM.

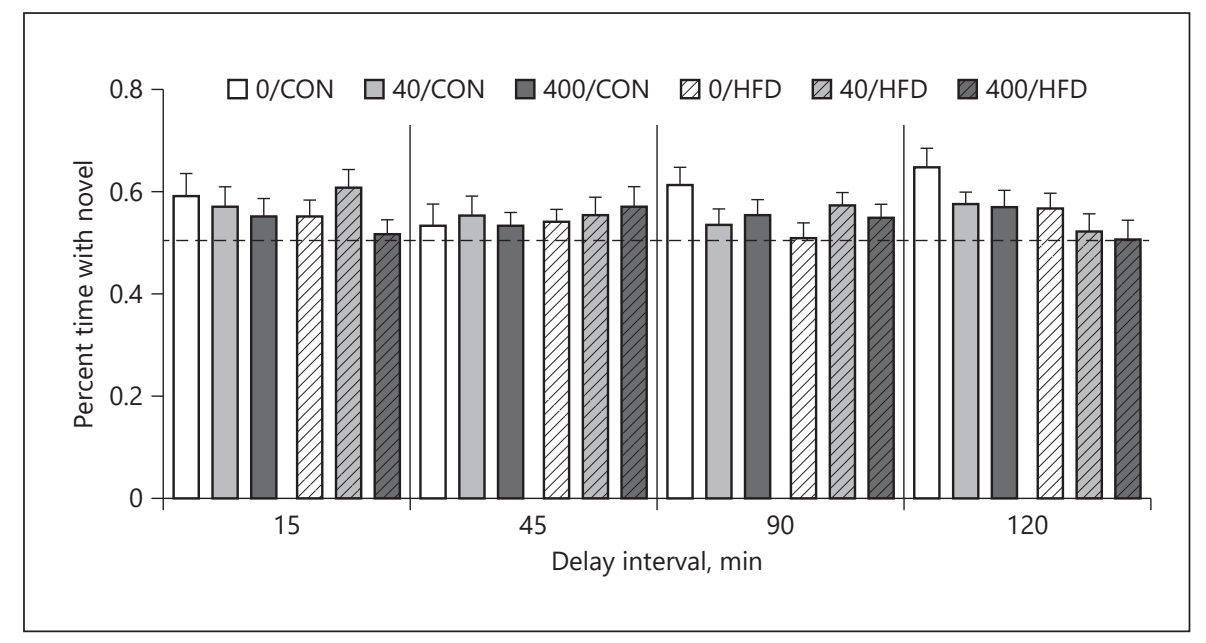

\section{Social Recognition}

There were no significant differences in social recognition based on either BPA or diet ( $p>0.05$; Fig. 5).

\section{Cytokine Levels in the P10 mPFC}

The results of the ELISAs on the mPFC of P10 pups are shown in Table 1 as a percent change compared to control animals (CON diet/0 BPA). There were main effects of sex in 7 of the 8 cytokines examined. Males had a higher percent change than females in the level of TNFa, TGF $\beta$, MCP-1, IL-1 $\alpha$, IL-15, and VEGF. Females had a higher percent change in the IL- 6 cytokine level than males. The only cytokine that did not show a sex difference was IL$1 \beta$. There was a significant main effect of diet on IL- $6, \mathrm{~F}(1$,
$70)=11.25, p<0.002$. There were no main effects of BPA on the levels of cytokines, but there were significant interactions between sex and BPA exposure (Fig. 6): TNFa, $\mathrm{F}(2,68)=4.09, p<0.03$; MCP-1, $\mathrm{F}(2,65)=5.93, p<0.005$, and VEGF, $\mathrm{F}(2,68)=6.81, p<0.003$. LSD post hoc comparisons found that males, but not females, had increased levels of TNFa, MCP-1, and VEGF following BPA exposure. Males had a significant increase in TNFa following both 40 and $400 \mu \mathrm{g} \mathrm{BPA} / \mathrm{kg}(p<0.03$ and $p<0.001$, respectively) and in MCP-1 and VEGF following $400 \mu \mathrm{g}$ $\mathrm{BPA} / \mathrm{kg}(p<0.006$ and $p<0.003$, respectively).

In order to assess the possible associations between maternal behavior and cytokine levels of the offspring, a two-tailed Spearman's correlation was conducted com- 
Table 1. Cytokine levels (percent change from control diet/0 BPA) in the mPFC of P10 pups with or without BPA treatment ( 0 , 40 , or $400 \mu \mathrm{g} / \mathrm{kg} /$ day)

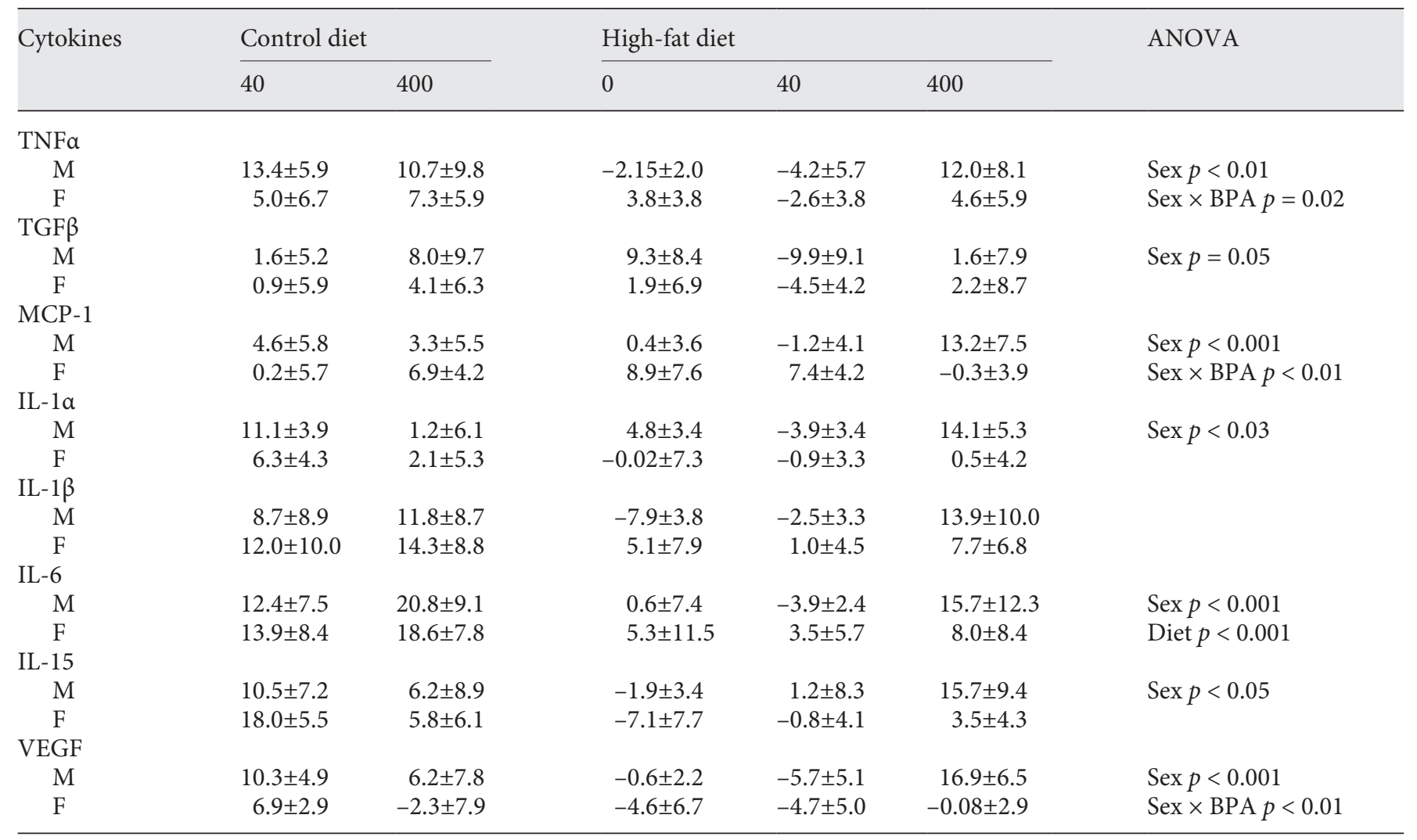

Values are expressed as the mean percent change from control $(0 \mu \mathrm{g} / \mathrm{kg} / \mathrm{day} \mathrm{BPA} /$ control diet $) \pm \mathrm{SEM}$. M, males; F, females.

paring maternal licking to each protein. Maternal licking was negatively correlated with levels of IL- $1 \alpha(r=-0.257$, $p<0.02)$, IL-15 $(r=-0.243, p<0.03)$, and VEGF $(r=$ $-0.249, p<0.02)$. The remaining cytokines were not significantly correlated with maternal licking.

\section{Gene Expression in the P10 mPFC}

The results of the qPCR analyses of the P10 mPFC are listed in Table 2. Females had higher expression than males in: Esr1 $(p<0.05)$, Sod1 $(p<0.04)$, Aif1 $(p<0.02)$, $C 4 a(p<0.001)$, and Casp3 $(p<0.005)$. There were main effects of BPA exposure in Esr1, $\mathrm{F}(2,89)=7.39, p<0.002$, and Sod $1, \mathrm{~F}(2,89)=3.75, p<0.03$. Post hoc comparisons found that animals exposed to $40 \mu \mathrm{g}$ BPA $/ \mathrm{kg}(p<0.02)$ and $400 \mu \mathrm{g} \mathrm{BPA} / \mathrm{kg}(p<0.001)$ had higher expression levels of Esr1 in the PFC than 0-BPA animals (Fig. 7a); likewise, Sod 1 expression was significantly higher following both 40 and $400 \mu \mathrm{g} \mathrm{BPA} / \mathrm{kg}$ than 0 BPA $(p<0.02)$. HFD exposure resulted in a significant decrease in gene expression of $\operatorname{Sod} 2 \mathrm{~F}(1,89)=6.85, p<0.02$.
The only significant interactions in gene expression between BPA treatment and diet were found in Errg, F(2, $89)=4.47, p<0.02$ (Fig. 7b), and Glrx, F(2, 89) = 3.46, $p<0.04$ (Fig. 7c). Post hoc analysis showed that the HFD/0-BPA group had higher Errglevels than both CON $\operatorname{diet} / 0$ BPA $(p<0.001), \mathrm{HFD} / 40 \mu \mathrm{g}$ BPA $/ \mathrm{kg} /$ day $(p<0.05)$. Glrx was higher following $400 \mu \mathrm{g}$ BPA treatment only in the HFD group $(p<0.05)$. The remainder of the genes did not show significant differences (Esr2, Ar, Star, Cyp11a1, Cat, and C4b).

In order to assess the possible associations between maternal behavior and resulting gene expression of the offspring, a two-tailed Spearman's correlation was conducted comparing each maternal behavior to each gene. None of the behaviors or gene expression levels were significantly correlated (data not shown).

\section{Gene Expression in the P90 Cortex}

The results of the gene expression analysis of the cortex on P90 are shown in Table 3. Females had a higher 


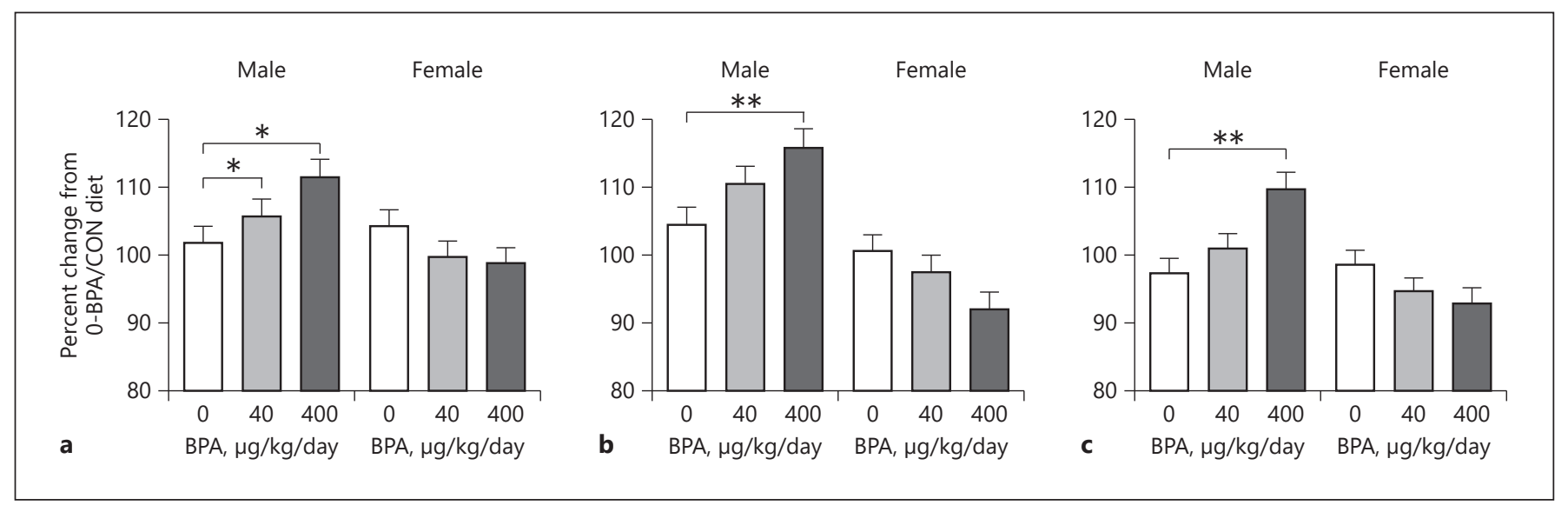

Fig. 6. The levels of proinflammatory cytokines that increased in males but not in females in the mPFC on P10 following perinatal BPA exposure (significant interactions between BPA and sex). The data are collapsed across diet. a Males exposed to 40 and $400 \mu \mathrm{g}$ $\mathrm{BPA} / \mathrm{kg} /$ day had higher levels of $\mathrm{TNF} \alpha$ than the 0-BPA group. b Males exposed to $400 \mu \mathrm{g} \mathrm{BPA} / \mathrm{kg} /$ day had higher levels of MCP1 than the 0-BPA groups. c Males exposed to $400 \mu \mathrm{g}$ BPA $/ \mathrm{kg} /$ day had higher levels of VEGF than the 0-BPA group. ${ }^{*} p<0.05 ; p<$ 0.006. Means \pm SEM.
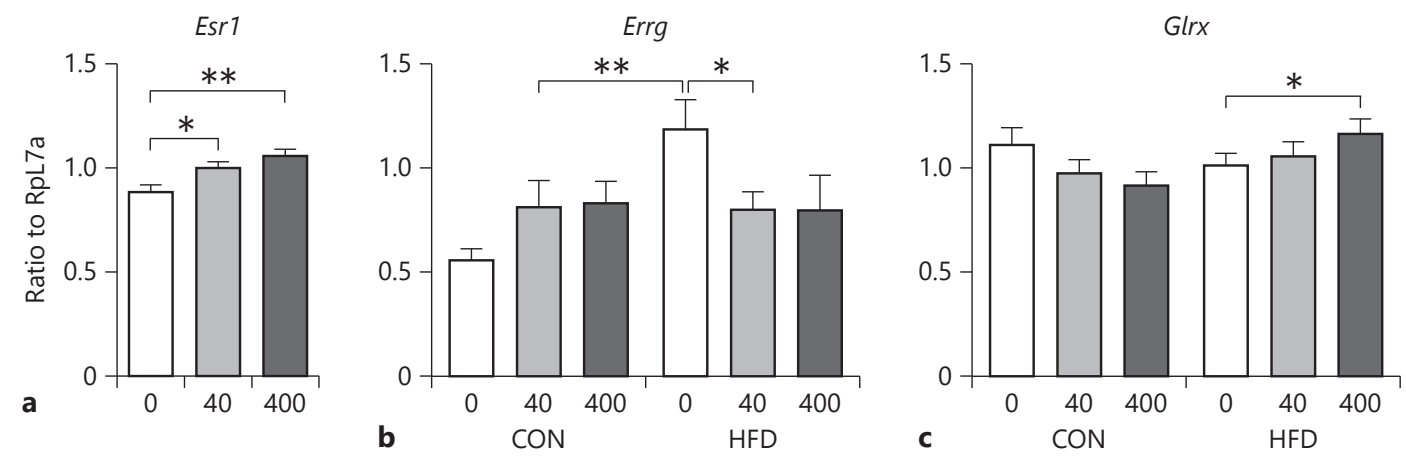

Fig. 7. Alterations in gene expression in the $\mathrm{mPFC}$ of $\mathrm{P} 10$ male and female pups following perinatal BPA $(0,40$, or $400 \mu \mathrm{g} / \mathrm{kg} /$ day $)$ and HFD. a Esr1 expression increased with perinatal exposure to BPA (BPA: $p<0.002)$. The data are collapsed across diet. $\mathbf{b}$ Errg expression was higher in HFD/0-BPA animals than in CON diet/0-BPA animals and in HFD $/ 40-\mu \mathrm{g}$ BPA $/ \mathrm{kg} /$ day BPA animals (diet $\times$ BPA: $p<0.02)$. c Glrx expression was increased in animals exposed to $\mathrm{HFD}$ and $400 \mu \mathrm{g} \mathrm{BPA} / \mathrm{kg} /$ day compared to HFD $/ 0-\mathrm{BPA}$ animals. No changes occurred in CON diet groups (diet $\times$ BPA: $p<0.04)$ ${ }^{*} p<0.05$; $^{* *} p<0.01$. level of gene expression in Sod2 $(p<0.001)$, Aif1 ( $p<$ $0.04)$, and $\operatorname{Cas} p 3(p=0.05)$, while males had higher levels of gene expression in $C 4 a(p<0.001)$ and $C 4 b(p<0.05)$. HFD resulted in an increase in the expression of genes related to hormone receptors, oxidative stress, and apoptosis, including Esr $1, \mathrm{~F}(1,66)=4.63, p<0.05 ; \operatorname{Errg}, \mathrm{F}(1$, $66)=4.37, p<0.05$; Cat, $\mathrm{F}(1,66)=8.92, p<0.005$; and Casp3, $\mathrm{F}(1,65)=4.74, p<0.05$. There were no main effects of BPA on any of the genes analyzed.
However, BPA interacted with HFD in several genes: $A r$, $\mathrm{F}(2,66)=3.82 ; p<0.05 ; E s r 2, \mathrm{~F}(2,66)=3.40 ; p<0.05$, Glrx, $\mathrm{F}(2,64)=3.48 ; p<0.05$. Post hoc tests on Ar showed a significant decrease in gene expression following perinatal HFD exposure compared to CON diet only in the 0-BPA group $(p<0.02)$. Further, $A r$ was significantly decreased between 0 and $40 \mu \mathrm{g}$ BPA $/ \mathrm{kg} /$ day $(p=0.05)$ only in the CON diet animals. Post hoc tests on Esr2 showed that only within the $\mathrm{CON}$ diet groups was there a significant reduction in the level of gene expression at $400 \mu \mathrm{g}$ compared to 
Table 2. Gene expression from the mPFC of P10 male (M) and female rats (F) with or without BPA treatment $(0,40$, or $400 \mu \mathrm{g} / \mathrm{kg} / \mathrm{day})$

\begin{tabular}{|c|c|c|c|c|c|c|c|}
\hline $\begin{array}{l}\text { Gene } \\
\text { expression }\end{array}$ & \multicolumn{3}{|c|}{ Control diet } & \multicolumn{3}{|c|}{ High-fat diet } & ANOVA \\
\hline \multicolumn{8}{|l|}{ Esr1 } \\
\hline M & $0.74 \pm 0.06$ & $0.99 \pm 0.02$ & $0.97 \pm 0.06$ & $0.85 \pm 0.04$ & $1.01 \pm 0.06$ & $1.08 \pm 0.04$ & $\operatorname{Sex} p<0.05$ \\
\hline $\mathrm{F}$ & $0.98 \pm 0.04$ & $0.99 \pm 0.06$ & $1.05 \pm 0.04$ & $0.96 \pm 0.06$ & $0.94 \pm 0.04$ & $1.13 \pm 0.11$ & $\mathrm{BPA} p<0.002$ \\
\hline $\mathrm{F}$ & $0.81 \pm 0.09$ & $0.75 \pm 0.06$ & $0.75 \pm 0.06$ & $0.89 \pm 0.12$ & $0.95 \pm 0.11$ & $0.88 \pm 0.10$ & \\
\hline \multicolumn{8}{|l|}{ Errg } \\
\hline $\mathrm{M}$ & $0.59 \pm 0.09$ & $0.91 \pm 0.18$ & $0.91 \pm 0.17$ & $1.24 \pm 0.24$ & $0.78 \pm 0.14$ & $0.79 \pm 0.21$ & Diet $\times$ BPA $p<0.02$ \\
\hline \multirow[t]{2}{*}{$\mathrm{F}$} & $0.52 \pm 0.06$ & $0.64 \pm 0.08$ & $0.75 \pm 0.10$ & $1.08 \pm 0.15$ & $0.87 \pm 0.11$ & $0.82 \pm 0.16$ & \\
\hline & & & & & & & Diet $\times$ BPA $p<0.02$ \\
\hline \multicolumn{8}{|r|}{ E } \\
\hline $\mathrm{F}$ & $1.46 \pm 0.09$ & $1.17 \pm 0.08$ & $1.20 \pm 0.11$ & $1.22 \pm 0.11$ & $1.13 \pm 0.08$ & $1.19 \pm 0.11$ & \\
\hline \multicolumn{8}{|l|}{ Cyp11a1 } \\
\hline $\mathrm{M}$ & $0.91 \pm 0.12$ & $0.65 \pm 0.10$ & $1.10 \pm 0.21$ & $1.14 \pm 0.21$ & $1.29 \pm 0.23$ & $1.18 \pm 0.28$ & \\
\hline $\mathrm{F}$ & $0.79 \pm 0.26$ & $1.37 \pm 0.20$ & $1.24 \pm 0.25$ & $1.24 \pm 0.15$ & $1.30 \pm 0.22$ & $0.89 \pm 0.03$ & \\
\hline
\end{tabular}

\section{Inflammation or oxidative stress markers}

Cat

$\begin{array}{cccccccc}\text { M } & 0.96 \pm 0.02 & 1.03 \pm 0.02 & 0.98 \pm 0.02 & 0.96 \pm 0.04 & 0.97 \pm 0.04 & 0.94 \pm 0.01 & \\ \text { F } & 1.03 \pm 0.04 & 1.00 \pm 0.02 & 1.04 \pm 0.03 & 0.98 \pm 0.02 & 0.98 \pm 0.01 & 1.04 \pm 0.06 & \\ \text { Sod1 } & & & & & & & \\ \text { M } & 0.86 \pm 0.06 & 0.99 \pm 0.03 & 0.96 \pm 0.02 & 0.91 \pm 0.03 & 1.01 \pm 0.04 & 1.03 \pm 0.03 & \text { Sex } p<0.04 \\ \text { F } & 1.00 \pm 0.01 & 1.04 \pm 0.04 & 0.97 \pm 0.05 & 0.96 \pm 0.02 & 1.03 \pm 0.03 & 1.07 \pm 0.04 & \text { BPA } p<0.03 \\ \text { Sod2 } & & & & & & & \\ \text { M } & 1.15 \pm 0.01 & 1.18 \pm 0.09 & 1.05 \pm 0.05 & 1.02 \pm 0.04 & 1.08 \pm 0.08 & 1.04 \pm 0.08 & \text { Diet } p<0.02 \\ \text { F } & 1.18 \pm 0.08 & 1.25 \pm 0.11 & 1.04 \pm 0.08 & 0.97 \pm 0.08 & 0.93 \pm 0.11 & 0.94 \pm 0.15 & \\ \text { Glrx } & & & & & & & \\ \text { M } & 1.06 \pm 0.03 & 1.01 \pm 0.03 & 1.00 \pm 0.01 & 0.95 \pm 0.05 & 1.02 \pm 0.04 & 1.05 \pm 0.07 & \text { Diet } \times \text { BPA } p<0.04 \\ \text { F } & 1.18 \pm 0.06 & 0.93 \pm 0.16 & 0.83 \pm 0.15 & 1.06 \pm 0.05 & 1.10 \pm 0.04 & 1.24 \pm 0.12 & \\ \text { Aif1 } & & & & & & & \\ \text { M } & 1.12 \pm 0.13 & 1.08 \pm 0.08 & 1.12 \pm 0.06 & 1.09 \pm 0.10 & 1.24 \pm 0.06 & 1.13 \pm 0.08 & \text { Sex } p<0.02 \\ \text { F } & 1.26 \pm 0.11 & 1.23 \pm 0.09 & 1.31 \pm 0.10 & 1.39 \pm 0.10 & 1.17 \pm 0.14 & 1.44 \pm 0.11 & \end{array}$

\section{Complement pathway}

$\mathrm{C} 4 \mathrm{a}$

\begin{tabular}{cccccccc}
$\mathrm{M}$ & $0.99 \pm 0.11$ & $0.78 \pm 0.04$ & $0.83 \pm 0.08$ & $0.82 \pm 0.05$ & $0.89 \pm 0.04$ & $0.93 \pm 0.07$ & Sex $p<0.001$ \\
$\mathrm{~F}$ & $1.00 \pm 0.06$ & $0.93 \pm 0.05$ & $1.13 \pm 0.14$ & $1.18 \pm 0.11$ & $0.97 \pm 0.05$ & $1.29 \pm 0.09$ & \\
$\mathrm{C} 4 \mathrm{~b}$ & & & & & & & \\
$\mathrm{M}$ & $1.34 \pm 0.14$ & $0.79 \pm 0.08$ & $0.94 \pm 0.15$ & $1.17 \pm 0.13$ & $1.13 \pm 0.11$ & $1.11 \pm 0.26$ & \\
$\mathrm{~F}$ & $0.95 \pm 0.18$ & $1.15 \pm 0.14$ & $1.19 \pm 0.12$ & $1.24 \pm 0.19$ & $1.08 \pm 0.13$ & $1.46 \pm 0.24$ & \\
\hline
\end{tabular}

\begin{tabular}{llllllll}
\hline $\begin{array}{l}\text { Apoptosis } \\
\text { Casp3 }\end{array}$ & & & & & & & \\
M & $0.94 \pm 0.03$ & $0.99 \pm 0.03$ & $0.88 \pm 0.03$ & $0.90 \pm 0.04$ & $0.89 \pm 0.07$ & $0.99 \pm 0.05$ & Sex $p<0.005$ \\
F & $1.00 \pm 0.05$ & $1.12 \pm 0.04$ & $1.03 \pm 0.07$ & $0.96 \pm 0.05$ & $1.00 \pm 0.03$ & $1.14 \pm 0.13$ & Diet $\times$ BPA $p=0.056$ \\
\hline
\end{tabular}

Data expressed as mean ratio to RpL7a \pm SEM.

10

Dev Neurosci 2019;41:1-16

DOI: $10.1159 / 000494879$
Wise/Hernández-Saavedra/Boas/Pan/ Juraska 
Table 3. Gene expression from the mPFC of adult male (M) and female rats (F) at P90with or without BPA treatment (0, 40, or 400 $\mu \mathrm{g} /$ $\mathrm{kg} / \mathrm{day})$

\begin{tabular}{llllllll}
\hline $\begin{array}{l}\text { Gene } \\
\text { expression }\end{array}$ & \multicolumn{3}{l}{ Control diet } & & \multicolumn{2}{l}{ High-fat diet } & ANOVA \\
\cline { 2 - 3 } & 0 & 40 & 400 & & 0 & 40 & 400 \\
\hline
\end{tabular}

\begin{tabular}{|c|c|c|c|c|c|c|c|}
\hline \multicolumn{8}{|c|}{$\begin{array}{l}\text { Hormone receptors and enzymes } \\
\text { Esr } 1\end{array}$} \\
\hline M & $0.92 \pm 0.12$ & $1.00 \pm 0.06$ & $0.81 \pm 0.08$ & $1.10 \pm 0.10$ & $0.98 \pm 0.08$ & $0.88 \pm 0.11$ & Diet $p<0.05$ \\
\hline $\mathrm{F}$ & $0.84 \pm 0.06$ & $0.84 \pm 0.12$ & $1.01 \pm 0.19$ & $0.86 \pm 0.14$ & $1.20 \pm 0.12$ & $1.32 \pm 0.08$ & $\mathrm{BPA} \times \operatorname{sex} p<0.05$ \\
\hline \multicolumn{8}{|l|}{ Esr2 } \\
\hline $\mathrm{M}$ & $1.10 \pm 0.09$ & $1.08 \pm 0.15$ & $0.76 \pm 0.11$ & $1.03 \pm 0.10$ & $0.91 \pm 0.16$ & $0.99 \pm 0.09$ & \multirow[t]{2}{*}{ Diet $\times$ BPA $p<0.05$} \\
\hline $\mathrm{F}$ & $1.05 \pm 0.08$ & $0.88 \pm 0.10$ & $0.78 \pm 0.07$ & $0.88 \pm 0.15$ & $1.01 \pm 0.08$ & $1.15 \pm 0.08$ & \\
\hline \multicolumn{8}{|l|}{ Errg } \\
\hline $\mathrm{M}$ & $1.19 \pm 0.14$ & $1.37 \pm 0.20$ & $1.05 \pm 0.15$ & $1.36 \pm 0.09$ & $1.32 \pm 0.11$ & $1.45 \pm 0.08$ & \multirow[t]{2}{*}{ Diet $p<0.05$} \\
\hline $\mathrm{F}$ & $1.48 \pm 0.15$ & $1.05 \pm 0.12$ & $1.23 \pm 0.11$ & $1.41 \pm 0.08$ & $1.50 \pm 0.13$ & $1.29 \pm 0.05$ & \\
\hline \multicolumn{8}{|l|}{$A r$} \\
\hline M & $1.00 \pm 0.11$ & $0.93 \pm 0.13$ & $0.74 \pm 0.09$ & $0.84 \pm 0.06$ & $0.88 \pm 0.03$ & $0.85 \pm 0.06$ & \multirow[t]{2}{*}{ Diet $\times$ BPA $p<0.03$} \\
\hline $\mathrm{F}$ & $1.13 \pm 0.07$ & $0.81 \pm 0.10$ & $1.00 \pm 0.10$ & $0.84 \pm 0.09$ & $1.07 \pm 0.10$ & $1.03 \pm 0.05$ & \\
\hline \multicolumn{8}{|l|}{ Star } \\
\hline M & $0.91 \pm 0.15$ & $0.95 \pm 0.20$ & $0.69 \pm 0.14$ & $0.90 \pm 0.14$ & $0.89 \pm 0.07$ & $0.98 \pm 0.10$ & \\
\hline $\mathrm{F}$ & $1.20 \pm 0.14$ & $0.81 \pm 0.10$ & $0.98 \pm 0.14$ & $0.83 \pm 0.12$ & $1.01 \pm 0.09$ & $1.06 \pm 0.03$ & \\
\hline \multicolumn{8}{|c|}{ Cyp11a1 } \\
\hline$M$ & $1.05 \pm 0.24$ & $1.26 \pm 0.19$ & $1.24 \pm 0.54$ & $0.77 \pm 0.25$ & $1.16 \pm 0.41$ & $1.13 \pm 0.49$ & \\
\hline $\mathrm{F}$ & $1.27 \pm 0.35$ & $1.37 \pm 0.40$ & $1.80 \pm 0.44$ & $1.85 \pm 0.70$ & $1.17 \pm 0.27$ & $1.67 \pm 0.38$ & \\
\hline
\end{tabular}

\section{Inflammation or oxidative stress markers}

Cat

Sod1

M $\quad 1.00 \pm 0.07$

$1.00 \pm 0.07$

$0.87 \pm 0.07$

$1.19 \pm 0.06$

$1.05 \pm 0.03 \quad 1.18 \pm 0.06$

Diet $p<0.005$

F

$1.07 \pm 0.05$

$1.00 \pm 0.08$

$0.98 \pm 0.12$

$1.16 \pm 0.10$

$1.13 \pm 0.06$

$1.12 \pm 0.04$

$0.95 \pm 0.04 \quad 1.07 \pm 0.10$

$0.97 \pm 0.02 \quad 0.98 \pm 0.05$

$0.91 \pm 0.10$

$1.05 \pm 0.08$

$1.00 \pm 0.09$

$1.10 \pm 0.09$

$1.11 \pm 0.04$

$\mathrm{M}$

$0.81 \pm 0.08$

$0.69 \pm 0.14$

$0.78 \pm 0.10$

$0.83 \pm 0.12$

$0.81 \pm 0.09 \quad 0.61 \pm 0.09$

$0.97 \pm 0.14$

$0.98 \pm 0.12$

$0.85 \pm 0.13$

$1.26 \pm 0.1$

$1.27 \pm 0.16$

Glrx

M

F

$1.08 \pm 0.12 \quad 1.00 \pm 0.11$

$0.90 \pm 0.10$

$0.96 \pm 0.08$

$0.88 \pm 0.07 \quad 0.87 \pm 0.07$

$0.92 \pm 0.08$

$1.20 \pm 0.08$

$1.30 \pm 0.13$

Diet $\times$ BPA $p<0.05$

Aif1

$\mathrm{M}$

$1.04 \pm 0.15$

$1.16 \pm 0.18$

$0.91 \pm 0.13$

$1.00 \pm 0.09$

$0.94 \pm 0.11$

$1.17 \pm 0.07$

$1.30 \pm 0.15 \quad 1.28 \pm 0.05$

$\operatorname{Sex} p<0.001$

$1.26 \pm 0.15$

$1.10 \pm 0.14$

\section{Complement pathway}

$\mathrm{C} 4 \mathrm{a}$

\begin{tabular}{cccccccc} 
M & $0.84 \pm 0.17$ & $1.16 \pm 0.10$ & $0.93 \pm 0.13$ & $1.19 \pm 0.16$ & $1.00 \pm 0.09$ & $1.34 \pm 0.19$ & Diet $\times$ BPA $\times \operatorname{sex} p<0.05$ \\
F & $0.85 \pm 0.04$ & $0.66 \pm 0.04$ & $0.64 \pm 0.06$ & $0.77 \pm 0.08$ & $0.91 \pm 0.08$ & $0.76 \pm 0.04$ & Sex $p<0.001$ \\
C4b & & & & & & \\
M & $0.90 \pm 0.08$ & $0.91 \pm 0.15$ & $0.93 \pm 0.24$ & $0.82 \pm 0.10$ & $0.81 \pm 0.14$ & $1.06 \pm 0.09$ & Sex $p<0.05$ \\
F & $0.81 \pm 0.04$ & $0.59 \pm 0.09$ & $0.80 \pm 0.11$ & $0.61 \pm 0.07$ & $0.91 \pm 0.11$ & $0.74 \pm 0.10$ & \\
\hline Apoptosis & & & & & & \\
Casp3 & & & & & & Diet $p<0.05$ \\
M & $0.80 \pm 0.06$ & $0.81 \pm 0.04$ & $0.69 \pm 0.06$ & $0.85 \pm 0.05$ & $0.74 \pm 0.04$ & $0.80 \pm 0.06$ & Sex $p=0.05$ \\
F & $0.87 \pm 0.05$ & $0.76 \pm 0.08$ & $0.74 \pm 0.07$ & $0.83 \pm 0.04$ & $0.97 \pm 0.05$ & $0.97 \pm 0.07$ & \\
\hline
\end{tabular}

Data expressed as mean ratio to RpL7a \pm SEM. 


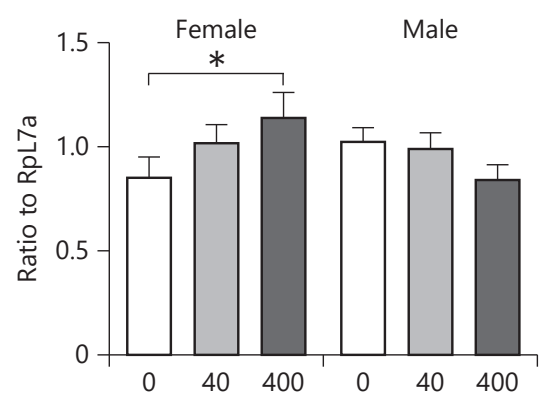

Fig. 8. The increased levels of gene Esr 1 expression in P90 females exposed to $400 \mu \mathrm{g} \mathrm{BPA} / \mathrm{kg} /$ day compared to controls; this did not occur in male animals. The data are collapsed across diet. ${ }^{*} p<0.02$.

0 BPA $(p<0.02)$. For Glrx, there was only a trend in post hoc tests between 0 and $400 \mu \mathrm{g}$ BPA within the CON diet $(p=0.057)$. In addition, there was a HFD-sex interaction in Glrx, $\mathrm{F}(1,64)=4.84 ; p<0.05$. Female animals in the HFD/400- $\mu$ g BPA group had a significant increase in the level of gene expression compared to the 0 -BPA group $(p<$ 0.04 ), while males did not have significant change.

A BPA-sex interaction was found in the expression of Esr $1, \mathrm{~F}(2,66)=3.61, p<0.05$, and a post hoc test revealed an increase in the level of gene expression in females following $400 \mu \mathrm{g} \mathrm{BPA} / \mathrm{kg} /$ day $(p<0.05)$, but there were no differences in males (Fig. 8). There was a three-way interaction of HFD, BPA, and sex in $C 4 a, \mathrm{~F}(2,65)=3.38, p<$ 0.04 . However, post hoc tests revealed no significant differences when treated groups were compared to controls (0 BPA). The interaction was driven by the different responses of females and males to diet and BPA, but none were significantly different from their own control.

No HFD or BPA effects or interactions were observed in the gene expression of Aif1, Star, Cyp11a21, Sod1, C4b, Sod2.

\section{Esr1 Gene Expression, premRNA Content and Promoter DNA Methylation}

The consistent increase in Esrl expression in females due to BPA exposure between P10 and P90 (Fig. 7a, 8) was further investigated through analysis of the methylation of the Esrl gene (Esrl) in the P90 mPFC tissue. Comparisons were made to males that did not have a long-term increase. The hypothesis was that the control (0-BPA) females had higher levels of methylation than those that had been exposed to BPA (especially at $400 \mu \mathrm{g}$ BPA/kg/ day). Despite the changes in gene expression, premRNA (the immature transcript before splicing to mRNA) content of Esr 1 in the PFC was not altered for males or female animals (online suppl. Fig. S3). Additionally, analysis of CG-rich sequences contained in the promoter of the rat gene revealed $4 \mathrm{CpG}$ dense islands and upstream regions. These regions were selected for DNA methylation analysis through methylation-specific PCR. Regions $1(+2043$ to $+2131 \mathrm{bp}$ ) and 4 (+4755 to $+4847 \mathrm{bp}$ ) showed the highest variation for females and males, but no significant effect was detected (online suppl. Fig. S1).

\section{miRNA Analysis of Esr1 in the mPFC}

Analysis of the 3 miRNAs associated with Esr1 revealed that the miRNA levels were not significantly altered by BPA administration as none of the miRNA expression levels were increased by 0.5 or more (online suppl. Fig. S4 and S5).

\section{Discussion}

The effects of simultaneous perinatal exposure to both BPA and HFD were investigated. BPA influenced adolescent play behavior, the EPM, and in the MPFC, inflammatory markers and gene expression on P10 and P90. HFD affected maternal behavior and the expression of a subset of genes. Notably, perinatal BPA and HFD rarely interacted on the measures in this study; the exception being the expression of a small number of genes that did not change in the same direction across ages.

\section{Maternal Behavior}

There were separate effects of HFD and BPA exposure on maternal behavior. The dams fed HFD spent less time away from the nest and marginally more time nursing. These effects of HFD on maternal care are supported by previous work showing an increase in nursing and decrease in resting away from nest with HFD ingestion $[8,26$, but see also 24]. Thus 45\% HFD during the metabolically demanding times of pregnancy and postnatal nursing can facilitate maternal behavior. BPA exposure at the higher dose, on the other hand, resulted in a near significant decrease in the amount of licking behavior exhibited by the dam. This mirrors a pattern in preliminary data from our laboratory in which $400 \mu \mathrm{g} \mathrm{BPA} / \mathrm{kg} /$ day resulted in less licking than $40 \mu \mathrm{g}$ BPA $/ \mathrm{kg} /$ day [47]. During the maternal observations, BPA was being administered directly to the pups but not to the dams. Thus, the decrease in licking by the dams may be due to BPA-induced changes in the pups, perhaps by alterations in behavior or olfactory cues. In-
Wise/Hernández-Saavedra/Boas/Pan/ Juraska 
creased maternal licking of pups has been linked to multiple behavioral and cellular alterations in the offspring, including a decrease in the behavioral stress response [1]. This is supported in our data by the negative correlation between maternal licking behavior and a reduction in inflammatory cytokines IL-1 $\alpha$, IL-15, and VEGF.

\section{Offspring Behaviors}

Perinatal BPA exposure resulted in several significant long-term alterations in offspring behavior, while perinatal exposure to $45 \%$ HFD did not in the current study. Periadolescent play behavior was decreased in animals exposed to BPA in the latter half of the 4 days of observation. Animals in the 0-BPA group spent more time engaged in play behaviors than the $400-\mu \mathrm{g} \mathrm{BPA} / \mathrm{kg}$ animals, while animals exposed to $40 \mu \mathrm{g}$ BPA $/ \mathrm{kg}$ spent more time alone than 0 -BPA animals, and animals exposed to $400 \mu \mathrm{g}$ $\mathrm{BPA} / \mathrm{kg}$ spent more time in passive contact than the 0 -BPA animals. These results of periadolescent play behavior are consistent with previous studies that found a decrease in play following 40- $\mu$ g BPA/kg exposure [48]. Ferguson et al. [49] also showed a pattern of decrease in play behavior following prenatal BPA exposure that did not reach significance at the lower doses used ( 2.5 and 25 $\mu \mathrm{g})$. Although overall sex differences were found with males spending more time playing and females spending more time alone, there were no sex-specific changes due to BPA in these measures.

Along with the striatum and medial amygdala, play behavior is mediated by the $\mathrm{mPFC}$, with inactivation of either the prelimbic or infralimbic subregions of the mPFC significantly reducing play $[50,51]$. Because play behavior was assessed weeks after BPA exposure ended, these data suggest that perinatal BPA exposure may alter the long-term structure of several neural regions including the $\mathrm{mPFC}$.

Evidence of an anxiolytic effect on the EPM due to BPA exposure in males was only uncovered when the CON diet group was analyzed separately, which supports previous literature that does not have a diet component $[46,52$, but see also 53,54]. Male animals in the 0-BPA group spent more time in the closed arms, but the males given $400-\mu \mathrm{g} \mathrm{BPA} / \mathrm{kg} /$ day increased their time on the open arms to female levels. We found that perinatal exposure to $400 \mu \mathrm{g} \mathrm{BPA} / \mathrm{kg} /$ day abolished the sex difference with an anxiolytic effect in males, which is in agreement with the literature [52].

Anxiety behavior is influenced by the mPFC through the cortical-amygdalar circuitry [55]. Both excitotoxic lesions and infusions of muscimol into the $\mathrm{mPFC}$, which inactivate $\mathrm{GABA}_{\mathrm{A}}$ receptors, reduce anxious behavior in the EPM $[56,57]$. Alterations in the anatomy of the mPFC by BPA could also affect anxiety behavior displayed in the EPM, and further research into the neuroanatomical effects of BPA on the mPFC is currently underway.

\section{Inflammatory Cytokines in the mPFC}

There was evidence in the present study that male, but not female, offspring had increased levels of proinflammatory cytokines TNF $\alpha$, MCP-1, and VEGF in the mPFC at the highest dose of BPA. The sex-specific response to perinatal BPA administration may be due to the sex differences in the immune system that are found early in development [reviewed in 58]. The increased presence of cytokines in the early developing brain may indicate inflammation due to BPA exposure. Inflammation may also shape the behavioral outcomes of the offspring. Previous research has found increases in anxiety-like behavior and IL-6 and TNFa levels following perinatal BPA exposure [6]. Here, the highest dose of BPA produced the increased levels of inflammation in the early postnatal male animals, but the adult male animals showed an anxiolytic effect instead of the predicted anxiogenic behavior on the EPM following BPA administration.

Interestingly, perinatal exposure to HFD resulted in a decrease in the protein level of IL-6 in the MPFC, which is contrary to what was reported in the hippocampus and frontal cortex of young animals [28]. However, our study was focused on the $\mathrm{mPFC}$, and the impact of perinatal HFD may be region dependent. Also, the necessary handling of pups for BPA administration during the first 10 postnatal days could have masked effects since early handling has a potent influence on later behavior [59], and its effects on inflammation are unknown. The current study adds to the evidence that BPA affects cortical inflammation during the early postnatal period and does not appear to interact with a $45 \%$ HFD during this exposure period.

\section{Gene Expression in the mPFC on P10 and P90}

Of the genes analyzed, only Esr 1 was comparably altered on P10, at the end of exposure, and on P90 in females, which may indicate long-term changes due to BPA. At P10, perinatal BPA exposure significantly increased the gene expression of Esr 1 in the MPFC in both sexes. The increase in Esr 1 expression seen here is similar but larger than that reported by Kundakovic et al. [16] who found a marginally significant U-shaped curvilinear effect on P28 in mice. Our study included direct BPA administration to the pups from P1 to P10 in addition to gestational exposure, which may explain the difference in strength of the results. The levels of Esr1 
mRNA expression start to decrease in normative studies of P10 rats [60, 61], but in the current study, animals exposed to the high dose of BPA had increased Esr 1 expression. Early developmental alterations in the expression of Esrl could change the sensitivity of the animals to estrogens, particularly if the increase in Esr1 persists, as we observed in the present study. This has also been postulated by Cao et al. [62], who found increases in Esr1 gene expression in the hypothalamus due to prenatal BPA exposure. On P90, Esr 1 continued to be higher in females that had perinatal BPA exposure. Interestingly, Esrl was the only hormone-related gene in which BPA effects were the same on both P10 and adulthood. The increase in the expression of Era in the mPFC of females persisted well after the final administration of BPA, which could suggest that BPA increases the level of protein transcription.

The consistent increase in Esr1 expression between P10 and P90 in females exposed to BPA was further explored. Several epigenetic mechanisms have been studied in regard to BPA in the brain, such as DNA methylation $[16,63,64]$ and histone modifications [65]. In the current study, no clear pattern of methylation was obtained within regions of the gene that defined BPA exposure. In line with this result, the premRNA, or unprocessed transcript, was not significantly different between BPA treatments, concordant with the low impact of DNA methylation on the transcriptional control of the Esr1 gene. DNA methylation mediates polymerase II binding and transcription factor accessibility to regulatory regions; however, the lack of active transcription could indicate that changes in mRNA expression are due to downstream stabilizing or destabilizing epigenetic regulators such as miRNA. However, of the 3 miRNAs identified, none were significantly increased in 0-BPA females, suggesting a different miRNA or mechanism is responsible for the long-term increase in Esr 1 expression.

Gene expression of another hormone-related receptor (Errg) was also influenced by BPA and HFD at each time point but not in the same direction. On P10, HFD increased the level of Errg expression, but in combination with BPA, the levels were not changed. In adulthood, there was no effect of BPA on Errg, but HFD resulted in decreased expression. ERR $\gamma$ is an orphan nuclear receptor, which does not bind estrogen [66] but strongly binds BPA [67]. It is likely that ERR $\gamma$ is, directly or indirectly, a part of the mechanism of action for BPA effects. When activated, ERR $\gamma$ is able to modulate estrogen receptordependent signaling and even stimulate estrogen response element-mediated transcription without the presence of another ligand [66]. ERR $\gamma$ has been only recently discovered, and the physiological impact of alterations in its gene expression is unknown. Higher levels of adiposity can increase the level of circulating estrogens [68] and the number of ER binding sites in peripheral tissues [69]. However, this is the first reported evidence of an increase in Errg expression with HFD. The dearth of information on the function of ERR $\gamma$ leaves the physiological effect of the changes in its expression unclear.

There were several genes that changed their expression in the $\mathrm{MPFC}$ due to sex and perinatal exposure to BPA and HFD on either P10 or P90. Expression levels of genes related to oxidative stress and inflammation were affected by BPA and HFD on P10 and P90 but rarely at both ages. The levels of Glrx expression showed an interaction between BPA and HFD with similar patterns on P10 and P90, however, which was significantly different from 0 -BPA. In addition, other genes related to inflammation were also altered on P90. Cat and Casp3 were increased following perinatal HFD, while $C 4 a$ was altered by HFD and BPA in a sex-specific manner. Males had an increased expression of $\mathrm{C} 4 \mathrm{a}$ following perinatal exposure to both BPA and HFD; however, females generally showed a decreased expression of $C 4 a$. Notably, neither HFD nor BPA caused an overall increase in the inflammatory markers, which suggests that not all of the inflammatory pathways are affected by BPA or HFD under these conditions.

\section{Conclusion}

The present study showed that perinatal exposure to BPA has effects on adolescent social behavior that tend to occur at the higher dose. Inflammatory markers and gene expression in the mPFC were also affected. BPA effects were often sex specific and more reliable at higher doses. Of particular interest is the lasting effect of BPA on the expression of Esr 1 in the mPFC. The impact of increased Esr1 expression in the mPFC is currently unknown but may indicate an increased response to estrogens. With regard to maternal diet, HFD ( $45 \%$ fat) restricted to the perinatal period had limited effects on the variables assessed in the offspring but did acutely affect the dams' maternal care. The effects of BPA and HFD rarely interacted in the current paradigm.

\section{Acknowledgments}

The authors would like to acknowledge Steven Rhoads for assistance with behavior scoring and Dr. Amogh Belagodu for assistance with ELISA training and analysis. We would also like to acknowledge the animal care staff at the Psychology Building.
Wise/Hernández-Saavedra/Boas/Pan/ Juraska 


\section{Disclosure Statement}

The authors have nothing to disclose.

\section{Funding Sources}

This work was supported by NIEHS P01 ES022848 Project 3 and USEPA 83543401 Project 3.

\section{References}

1 Liu D, Diorio J, Tannenbaum B, Caldji C, Francis D, Freedman A, et al. Maternal care, hippocampal glucocorticoid receptors, and hypothalamic-pituitary-adrenal responses to stress. Science. 1997 Sep;277(5332):1659-62.

2 Caldji C, Tannenbaum B, Sharma S, Francis D, Plotsky PM, Meaney MJ. Maternal care during infancy regulates the development of neural systems mediating the expression of fearfulness in the rat. Proc Natl Acad Sci USA. 1998 Apr;95(9):5335-40.

3 Sanchez MM. The impact of early adverse care on HPA axis development: nonhuman primate models. Horm Behav. 2006 Nov; 50(4):623-31.

4 McGowan PO, Sasaki A, D’Alessio AC, Dymov S, Labonté B, Szyf M, et al. Epigenetic regulation of the glucocorticoid receptor in human brain associates with childhood abuse. Nat Neurosci. 2009 Mar;12(3):342-8.

5 Holladay SD, Xiao S, Diao H, Barber J, Nagy $\mathrm{T}, \mathrm{Ye} \mathrm{X}$, et al. Perinatal bisphenol A exposure in C57B6/129svj male mice: potential altered cytokine/chemokine production in adulthood. Int J Environ Res Public Health. 2010 Jul;7(7):2845-52.

6 Luo G, Wang S, Li Z, Wei R, Zhang L, Liu H, et al. Maternal bisphenol a diet induces anxiety-like behavior in female juvenile with neuroimmune activation. Toxicol Sci. 2014 Aug; 140(2):364-73.

7 Bolton JL, Bilbo SD. Developmental programming of brain and behavior by perinatal diet: focus on inflammatory mechanisms. Dialogues Clin Neurosci. 2014 Sep;16(3):30720.

8 Kougias DG, Cortes LR, Moody L, Rhoads S, Pan YX, Juraska JM. Effects of perinatal exposure to phthalates and a high-fat diet on maternal behavior and pup development and social play. Endocrinology. 2018 Feb;159(2): 1088-105.

9 Vandenberg LN, Hauser R, Marcus M, Olea $\mathrm{N}$, Welshons WV. Human exposure to bisphenol A (BPA). Reprod Toxicol. 2007 AugSep;24(2):139-77.

10 Takayanagi S, Tokunaga T, Liu X, Okada H, Matsushima A, Shimohigashi Y. Endocrine disruptor bisphenol A strongly binds to human estrogen-related receptor gamma (ERRgamma) with high constitutive activity. Toxicol Lett. 2006 Dec;167(2):95-105.

11 Kuiper GG, Lemmen JG, Carlsson B, Corton JC, Safe SH, van der Saag PT, et al. Interaction of estrogenic chemicals and phytoestrogens with estrogen receptor beta. Endocrinology. 1998 Oct;139(10):4252-63.
12 Gould JC, Leonard LS, Maness SC, Wagner BL, Conner K, Zacharewski T, et al. Bisphenol A interacts with the estrogen receptor alpha in a distinct manner from estradiol. Mol Cell Endocrinol. 1998 Jul;142(1-2):203-14.

13 Sohoni P, Sumpter JP. Several environmental oestrogens are also anti-androgens. J Endocrinol. 1998 Sep;158(3):327-39.

14 Moriyama K, Tagami T, Akamizu T, Usui T, Saijo M, Kanamoto N, et al. Thyroid hormone action is disrupted by bisphenol A as an antagonist. J Clin Endocrinol Metab. 2002 Nov; 87(11):5185-90.

15 Della Seta D, Minder I, Dessì-Fulgheri F, Farabollini F. Bisphenol-A exposure during pregnancy and lactation affects maternal behavior in rats. Brain Res Bull. 2005 Apr;65(3): 255-60.

16 Kundakovic M, Gudsnuk K, Franks B, Madrid J, Miller RL, Perera FP, et al. Sex-specific epigenetic disruption and behavioral changes following low-dose in utero bisphenol A exposure. Proc Natl Acad Sci USA. 2013 Jun; 110(24):9956-61.

17 Dessì-Fulgheri F, Porrini S, Farabollini F. Effects of perinatal exposure to bisphenol A on play behavior of female and male juvenile rats. Environ Health Perspect. 2002 Jun;110 Suppl 3:403-7.

18 Kubo K, Arai O, Omura M, Watanabe R, Ogata R, Aou S. Low dose effects of bisphenol A on sexual differentiation of the brain and behavior in rats. Neurosci Res. 2003 Mar;45(3): $345-56$.

19 Rubin BS, Lenkowski JR, Schaeberle CM, Vandenberg LN, Ronsheim PM, Soto AM. Evidence of altered brain sexual differentiation in mice exposed perinatally to low, environmentally relevant levels of bisphenol A. Endocrinology. 2006 Aug;147(8):3681-91.

20 Matsuda S, Matsuzawa D, Ishii D, Tomizawa $\mathrm{H}$, Sutoh C, Nakazawa K, et al. Effects of perinatal exposure to low dose of bisphenol A on anxiety like behavior and dopamine metabolites in brain. Prog Neuropsychopharmacol Biol Psychiatry. 2012 Dec;39(2):273-9.

21 McCaffrey KA, Jones B, Mabrey N, Weiss B, Swan SH, Patisaul HB. Sex specific impact of perinatal bisphenol A (BPA) exposure over a range of orally administered doses on rat hypothalamic sexual differentiation. Neurotoxicology. 2013 May;36:55-62.
22 Sadowski RN, Wise LM, Park PY, Schantz SL, Juraska JM. Early exposure to bisphenol A alters neuron and glia number in the rat prefrontal cortex of adult males, but not females. Neuroscience. 2014 Oct;279:122-31.

23 Castro B, Sánchez P, Miranda MT, Torres JM, Ortega E. Identification of dopamine- and serotonin-related genes modulated by bisphenol $\mathrm{A}$ in the prefrontal cortex of male rats. Chemosphere. 2015 Nov;139:235-9.

24 Connor KL, Vickers MH, Beltrand J, Meaney MJ, Sloboda DM. Nature, nurture or nutrition? Impact of maternal nutrition on maternal care, offspring development and reproductive function. J Physiol. 2012 May;590(9): 2167-80.

25 Bellisario V, Panetta P, Balsevich G, Baumann V, Noble J, Raggi C, et al. High-fat diet during pregnancy acts as a stressor increasing maternal glucocorticoids' signaling to the fetus and disrupting maternal behavior in a mouse model. Psychoneuroendocrinology. 2015;61: 10.

26 Purcell RH, Sun B, Pass LL, Power ML, Moran TH, Tamashiro KL. Maternal stress and highfat diet effect on maternal behavior, milk composition, and pup ingestive behavior. Physiol Behav. 2011 Sep;104(3):474-9.

27 Hehar H, Ma I, Mychasiuk R. Effects of metabolic programming on juvenile play behavior and gene expression in the prefrontal cortex of rats. Dev Neurosci. 2016;38(2):96-104.

28 Bilbo SD, Tsang V. Enduring consequences of maternal obesity for brain inflammation and behavior of offspring. FASEB J. 2010 Jun; 24(6):2104-15.

29 Sullivan EL, Grayson B, Takahashi D, Robertson N, Maier A, Bethea CL, et al. Chronic consumption of a high-fat diet during pregnancy causes perturbations in the serotonergic system and increased anxiety-like behavior in nonhuman primate offspring. J Neurosci. 2010 Mar;30(10):3826-30.

30 White CL, Pistell PJ, Purpera MN, Gupta S, Fernandez-Kim SO, Hise TL, et al. Effects of high fat diet on Morris maze performance, oxidative stress, and inflammation in rats: contributions of maternal diet. Neurobiol Dis. 2009 Jul;35(1):3-13.

31 Page KC, Jones EK, Anday EK. Maternal and postweaning high-fat diets disturb hippocampal gene expression, learning, and memory function. Am J Physiol Regul Integr Comp Physiol. 2014 Apr;306(8):R527-37. 
32 Yu M, Jiang M, Yang C, Wu Y, Liu Y, Cui Y, et al. Maternal high-fat diet affects Msi/ Notch/Hes signaling in neural stem cells of offspring mice. J Nutr Biochem. 2014 Feb; 25(2):227-31.

33 Vucetic Z, Kimmel J, Totoki K, Hollenbeck E, Reyes TM. Maternal high-fat diet alters methylation and gene expression of dopamine and opioid-related genes. Endocrinology. 2010 Oct;151(10):4756-64.

34 Morselli E, Fuente-Martin E, Finan B, Kim M, Frank A, Garcia-Caceres C, et al. Hypothalamic PGC-1a protects against high-fat diet exposure by regulating ERa. Cell Reports. 2014 Oct;9(2):633-45.

35 Courchesne E, Mouton PR, Calhoun ME, Semendeferi K, Ahrens-Barbeau C, Hallet MJ, et al. Neuron number and size in prefrontal cortex of children with autism. JAMA. 2011 Nov; 306(18):2001-10.

36 Wise LM, Sadowski RN, Kim T, Willing J, Juraska JM. Long-term effects of adolescent exposure to bisphenol A on neuron and glia number in the rat prefrontal cortex: differences between the sexes and cell type. Neurotoxicology. 2016 Mar;53:186-92.

37 Ryan B. Developmental Exposure to Environmental Estrogens Alters Adult Behavior in Female Rodents. 2005. PhD. North Carolina State University; thesis. https://catalog.lib. ncsu.edu/record/NCSU1856644

38 Doerge DR, Vanlandingham M, Twaddle NC, Delclos KB. Lactational transfer of bisphenol A in Sprague-Dawley rats. Toxicol Lett. 2010 Dec;199(3):372-6.

39 Doerge DR, Twaddle NC, Vanlandingham M, Brown RP, Fisher JW. Distribution of bisphenol A into tissues of adult, neonatal, and fetal Sprague-Dawley rats. Toxicol Appl Pharmacol. 2011 Sep;255(3):261-70.

40 Mita L, Baldi A, Diano N, Viggiano E, Portaccio M, Nicolucci C, et al. Differential accumulation of BPA in some tissues of offspring of Balb-C mice exposed to different BPA doses. Environ Toxicol Pharmacol. 2012 Jan;33(1): 9-15.

41 Freedman MR, King J, Kennedy E. Popular diets: a scientific review. Obes Res. 2001 Mar; 9 Suppl 1:1S-40S.

42 Taylor PV, Veenema AH, Paul MJ, Bredewold R, Isaacs S, de Vries GJ. Sexually dimorphic effects of a prenatal immune challenge on social play and vasopressin expression in juvenile rats. Biol Sex Differ. 2012 Jun;3(1):15.

43 Wolstenholme JT, Taylor JA, Shetty SR, Edwards M, Connelly JJ, Rissman EF. Gestational exposure to low dose bisphenol A alters social behavior in juvenile mice. PLoS One. 2011;6(9):e25448.

44 Li LC, Dahiya R. MethPrimer: designing primers for methylation PCRs. Bioinformatics. 2002 Nov; 18(11):1427-31.

45 Imhof JT, Coelho ZM, Schmitt ML, Morato GS, Carobrez AP. Influence of gender and age on performance of rats in the elevated plus maze apparatus. Behav Brain Res. 1993 Sep; 56(2):177-80
46 Farabollini F, Porrini S, Dessì-Fulgherit F. Perinatal exposure to the estrogenic pollutant bisphenol A affects behavior in male and female rats. Pharmacol Biochem Behav. 1999 Dec;64(4):687-94.

47 Sadowski RN, Lowry NC, Park PY, Neese SL Schantz SL, Juraska JM. Low doses of bisphenol A during gestation and early development alters maternal behavior in Long Evans hooded rats. Program No. 86.01. 2011 Neuroscience Meeting Planner. Washington, DC: Society for Neuroscience, 2011. Online.

48 Porrini S, Belloni V, Della Seta D, Farabollini F, Giannelli G, Dessi-Fulgheri F. Early exposure to a low dose of bisphenol A affects sociosexual behavior of juvenile female rats. Brain Res Bull. 2005 Apr;65(3):261-6.

49 Ferguson SA, Law CD, Kissling GE. Developmental treatment with ethinyl estradiol, but not bisphenol A, causes alterations in sexually dimorphic behaviors in male and female Sprague Dawley rats. Toxicol Sci. 2014 Aug; 140(2):374-92.

50 van Kerkhof LW, Damsteegt R, Trezza V, Voorn P, Vanderschuren LJ. Social play behavior in adolescent rats is mediated by functional activity in medial prefrontal cortex and striatum. Neuropsychopharmacology. 2013 Sep;38(10):1899-909.

51 Vanderschuren LJ, Achterberg EJ, Trezza V. The neurobiology of social play and its rewarding value in rats. Neurosci Biobehav Rev. 2016 Nov; 70:86-105.

52 Jones BA, Watson NV. Perinatal BPA exposure demasculinizes males in measures of affect but has no effect on water maze learning in adulthood. Horm Behav. 2012 Apr;61(4): 605-10.

53 Rebuli ME, Camacho L, Adonay ME, Reif DM, Aylor DL, Patisaul HB. Impact of lowdose oral exposure to bisphenol A (BPA) on juvenile and adult rat exploratory and anxiety behavior: A CLARITY-BPA Consortium Study. Toxicol Sci. 2015 Dec;148(2):341-54.

54 Harris EP, Allardice HA, Schenk AK, Rissman EF. Effects of maternal or paternal bisphenol A exposure of offspring behavior. Horm Behav. Forthcoming 2018 May;101:68-76.

55 Tovote P, Fadok JP, Lüthi A. Neuronal circuits for fear and anxiety. Nat Rev Neurosci. 2015 Jun; 16(6):317-31

56 Shah AA, Treit D. Excitotoxic lesions of the medial prefrontal cortex attenuate fear responses in the elevated-plus maze, social interaction and shock probe burying tests. Brain Res. 2003 Apr;969(1-2):183-94.

57 Shah AA, Sjovold T, Treit D. Inactivation of the medial prefrontal cortex with the GABAA receptor agonist muscimol increases openarm activity in the elevated plus-maze and attenuates shock-probe burying in rats. Brain Res. 2004 Nov;1028(1):112-5.
58 Nelson LH, Lenz KM. The immune system as a novel regulator of sex differences in brain and behavioral development. J Neurosci Res. 2017 Jan;95(1-2):447-61.

59 Raineki C, Lucion AB, Weinberg J. Neonatal handling: an overview of the positive and negative effects. Dev Psychobiol. 2014 Dec;56(8): 1613-25.

60 Wilson ME, Westberry JM, Trout AL. Estrogen receptor-alpha gene expression in the cortex: sex differences during development and in adulthood. Horm Behav. 2011 Mar: 59(3):353-7.

61 Westberry JM, Wilson ME. Regulation of estrogen receptor alpha gene expression in the mouse prefrontal cortex during early postnatal development. Neurogenetics. 2012 May; 13(2):159-67.

62 Cao J, Mickens JA, McCaffrey KA, Leyrer SM, Patisaul HB. Neonatal Bisphenol A exposure alters sexually dimorphic gene expression in the postnatal rat hypothalamus. Neurotoxicology. 2012 Jan;33(1):23-36.

63 Drobná Z, Henriksen AD, Wolstenholme JT, Montiel C, Lambeth PS, Shang S, et al. Transgenerational effects of Bisphenol A on gene expression and DNA methylation of imprinted genes in brain. Endocrinology. 2018 Jan; 159(1):132-44.

64 Yaoi T, Itoh K, Nakamura K, Ogi H, Fujiwara Y, Fushiki S. Genome-wide analysis of epigenomic alterations in fetal mouse forebrain after exposure to low doses of bisphenol A. Biochem Biophys Res Commun. 2008 Nov; 376(3):563-7.

65 Kumar D, Thakur MK. Effect of perinatal exposure to Bisphenol-A on DNA methylation and histone acetylation in cerebral cortex and hippocampus of postnatal male mice. J Toxicol Sci. 2017;42(3):281-9.

66 Ijichi N, Shigekawa T, Ikeda K, Horie-Inoue K, Fujimura T, Tsuda H, et al. Estrogen-related receptor $\gamma$ modulates cell proliferation and estrogen signaling in breast cancer. J Steroid Biochem Mol Biol. 2011 Jan;123(1-2):1-7.

67 Matsushima A, Kakuta Y, Teramoto T, Koshiba T, Liu X, Okada H, et al. Structural evidence for endocrine disruptor bisphenol A binding to human nuclear receptor ERR gamma. J Biochem. 2007 Oct;142(4):517-24.

68 Adlercreutz H, Gorbach SL, Goldin BR, Woods MN, Dwyer JT, Hämäläinen E. Estrogen metabolism and excretion in Oriental and Caucasian women. J Natl Cancer Inst. 1994 Jul;86(14):1076-82.

69 Hilakivi-Clarke L, Stoica A, Raygada M, Martin MB. Consumption of a high-fat diet alters estrogen receptor content, protein kinase $\mathrm{C}$ activity, and mammary gland morphology in virgin and pregnant mice and female offspring. Cancer Res. 1998 Feb;58(4): 654-60. 